Canadian Journal of Fisheries and Aquatic Sciences

Canadian

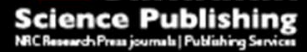

Journal canadien des sciences halieutiques et aquatiques

\title{
An integrated tagging model to estimate mortality rates of Albemarle Sound-Roanoke River striped bass
}

\begin{tabular}{|r|l|}
\hline Journal: & Canadian Journal of Fisheries and Aquatic Sciences \\
\hline Manuscript ID & cjfas-2016-0141.R2 \\
\hline Manuscript Type: & Article \\
\hline Date Submitted by the Author: & $15-$ Nov-2016 \\
\hline Complete List of Authors: & $\begin{array}{l}\text { Harris, Julianne; U.S. Fish and Wildlife Service, Columbia River Fish and } \\
\text { Wildlife Conservation Office } \\
\text { Hightower, Joseph; North Carolina State University, Department of Applied } \\
\text { Ecology }\end{array}$ \\
\hline Keyword: & $\begin{array}{l}\text { MORTALITY < General, TAGGING < General, Multistate, BAYESIAN } \\
\text { STATISTICS < General, Striped bass }\end{array}$ \\
\hline
\end{tabular}


1

2

3

4

5

6

7

8

9

10

11

12

13

14 "Corresponding Author: Julianne Harris

15 Current contact information: U. S. Fish and Wildlife Service, Columbia River Fish and Wildlife

16 Conservation Office, 1211 SE Cardinal Ct., Suite 100, Vancouver WA 98683

17 Email: julianne harris@fws.gov, Phone: 360-604-2551, Fax: 360-604-2505 


\section{Abstract}

We developed an integrated tagging model to estimate mortality rates and run sizes of Albemarle Sound-Roanoke River striped bass (Morone saxatilis) including: 1) a multistate

21 component for telemetered fish with a high reward external tag; 2) tag return components for

22 fish with a low reward external or PIT tag; and 3) catch-at-age data. Total annual instantaneous

23 mortality was 1.08 for resident (458-899 $\mathrm{mm} \mathrm{TL})$ and 0.45 for anadromous ( $\geq 900 \mathrm{~mm} \mathrm{TL})$

24 individuals. Annual instantaneous natural mortality was higher for resident $(0.70)$ than

25 anadromous (0.21) fish due to high summer mortality in Albemarle Sound. Natural mortality for

26 residents was substantially higher than currently assumed for stock assessment. Monthly

27 fishing mortality from multiple sectors (including catch and release) corresponded to seasonal

28 periods of legal harvest. Run size estimates were 499-715 thousand. Results and simulation

29 suggest increasing sample size for the multistate component increases accuracy and precision

30 of annual estimates and low reward tags are valuable for estimating monthly fishing mortality

31 rates among sectors. Our results suggest that integrated tagging models can produce seasonal

32 and annual mortality estimates needed for stock assessment and management. 


\section{Introduction}

Accurate and precise estimates of fishing and natural mortality are essential for fisheries management, but can be challenging to obtain, especially for migratory species that support multiple fisheries. Rates have effectively been estimated by external and internal tag studies (Pollock et al. 2004; Bacheler et al. 2009; Hightower and Pollock 2013; Kerns et al. 2016).

Typically, tag studies use a fisheries-dependent approach, in which an externally-visible tag can

be reported when the fish is caught. With data on tag reporting rate, reported tags directly inform on fishing mortality rates; however, tag returns are less informative for estimating natural mortality rates since both natural deaths and live fish are not observed. Changes in reporting rate and periods without harvest make examining seasonal patterns in natural mortality difficult or impossible. In contrast, internal tags such as passive integrated transponder (PIT) and acoustic tags are often only detected by scientists and mortality is assessed by the pattern of tag detection. Natural mortality can be detected in small, searchable systems, by repeatedly detecting a non-moving acoustic tag, but fishing mortality is usually only assessed indirectly by

47 the disappearance of a tagged fish (Hightower et al. 2001; Hightower and Pollock 2013). With only internal tags, mortality rates from multiple fisheries cannot be differentiated and natural mortality cannot be differentiated from catch and release mortality. Thus, a study incorporating a single approach may not directly produce all needed information for a stock that supports multiple fisheries over an extensive and unsearchable geographic area, such as Albemarle

52 Sound-Roanoke River (AS-RR) striped bass, Morone saxatilis.

Striped bass support intensive and economically valuable fisheries in many rivers and coastal areas along the Atlantic Coast in Canada and the USA (Patrick et al. 2006). Fisheries for the AS-RR stock are managed in North Carolina by a total allowable catch, seasonal open periods, length limits, bag limits, and gear limits. Legally, striped bass can be harvested

57 (commercially and recreationally) in Albemarle and Pamlico sounds October 1 to April 30 if they 58 are $458 \mathrm{~mm}$ TL (i.e., 18 inches) or larger. Spawning occurs in the Roanoke River in March-May 
(Hassler et al. 1981; Carmichael et al. 1998) and striped bass can be recreationally harvested in the Roanoke River in March-April. In the Roanoke River, the minimum size limit is $458 \mathrm{~mm}$ TL and there is an exclusive slot of 559-686 mm TL (i.e., 22-27 inches). Despite extensive research on this stock, an assumed rate for annual natural mortality is currently used for stock assessment; information on natural and fishing mortality rates would improve management of this valuable species and stock (Takade-Heumacher 2010; Mroch and Godwin 2014).

In many populations, the probability that an individual striped bass is anadromous increases with fish size (Callihan et al. 2014). For the AS-RR stock, most juvenile and small mature striped bass remain in the AS-RR throughout the year. Individuals can become anadromous at $600 \mathrm{~mm}$ total length (TL), although most do not conduct coastal migrations until 800-900 mm TL (Haeseker et al. 1996; Callihan et al. 2014; Callihan et al. 2015). Anadromous individuals migrate in the Atlantic Ocean as far north as Massachusetts during non-spawning periods, only returning to the AS-RR for about a month during the spawning run (Callihan et al. 2014; Callihan et al. 2015). Despite spatial overlap with other Atlantic coast striped bass populations during non-spawning periods, the AS-RR population is considered a distinct stock (Waldman et al. 2012; Gauthier et al. 2013; Kneebone et al. 2014) and anadromous individuals from the AS-RR stock return annually to spawn in the Roanoke River (Callihan et al. 2015). Considering vast differences in behavior, it is unclear if anadromous individuals experience mortality rates similar to AS-RR residents.

We developed integrated tagging models to estimate mortality rates and run sizes of resident and anadromous AS-RR striped bass to aid assessment and management of this important stock. Integrated models jointly analyze multiple independent datasets to estimate a variety of demographic parameters. Using an integrated model to estimate common parameters can increase estimate precision; however, integrated models can also estimate parameters inestimable by only one likelihood component (Abadi et al. 2010; Maunder and Punt 2013). We developed the first integrated tagging model to combine: 1) passive sonic detections 
on stationary receivers with returns of high reward external tags evaluated by a multistate submodel; 2) low reward external tags and passive integrated transponder (PIT) tags with harvest data, evaluated using tag return submodels; and 3) catch-at-age data evaluated by a catch curve submodel (Fig. 1). We also used simulation to evaluate accuracy and precision of an integrated tagging model including passive detections of fish with sonic tags and high reward external tags and other fish with low reward external tags. Specific objectives were to: 1) estimate seasonal natural mortality and monthly fishing mortality rates for AS-RR striped bass; 2) produce run-size estimates for striped bass in the Roanoke River; 3) compare mortality rates of resident AS-RR striped bass to those of anadromous individuals in the stock; and 4) evaluate accuracy and precision of an integrated tagging model to estimate seasonal (i.e., to understand mortality biologically) and annual (i.e., to aid stock assessment) mortality rates. Our study is the first to evaluate how this type of integrated model including a combination of passive detections of sonic tags and returns of high and low reward tags can be used to estimate seasonal natural mortality rates, fishing mortality rates from multiple sectors, and run sizes. Our approach was very useful for estimating mortality rates and stock status for AS-RR striped bass and would similarly be useful for other fish populations that are migratory, have an extensive (i.e., manually unsearchable) range, or support multiple fisheries.

\section{Methods}

\section{Field sampling}

For sonic and high (\$100) reward tagging, 143 striped bass (445-695 mm TL) were caught by hook and line and commercial pound net in western Albemarle Sound February-April, 2011 and 2012 (Table 1; Fig. 2). In addition, two males (750 and $873 \mathrm{~mm} \mathrm{TL}$ ) and 14 females (939-1146 mm TL) were collected by electrofishing in April and May of 2011 and 2012 on the spawning grounds in Weldon for sonic and high reward tagging (Fig. 2). To implant a Vemco V13-L sonic tag (13 mm diameter, $36 \mathrm{~mm}$ length, and $11 \mathrm{~g}$ in air) and a $23 \mathrm{~mm}$ half duplex PIT 
111 tag, each striped bass was anaesthetized with buffered MS-222, measured for TL, and placed in

112 a cradle with its gills submerged in water. In 2011, sonic tags had a random delay (i.e., time

113 between signal submissions or "pings") of 30-90 seconds and an expected battery life of 622

114 days; in 2012, the random delay was $60-120$ seconds and the battery life was 880 days. To

115 implant the internal tags (i.e., sonic and PIT), a small incision ( $2 \mathrm{~cm}$ ) was made on the fish's

116 ventral side between the pelvic and pectoral fins. After implantation, this incision was closed by

117 2-3 interrupted sutures with two wraps on each throw (Deters et al. 2012). Another small

118 incision $(<1 \mathrm{~cm})$ was made on the left side below the musculature for a high $(\$ 100)$ reward

119 internal anchor tag.

120 Returns and detections of sonic and high reward tagged striped bass contributed to

121 estimates of mortality. External high reward tags had instructions to cut the tag and call North

122 Carolina State University (NCSU) for the reward, then keep or release the fish, as planned. We

123 assumed that each captured striped bass with a high reward tag was reported and that the

124 information reported regarding capture was without error. Specifically, we assumed that a

125 reward of $\$ 100$ was sufficient to ensure a reporting rate of $100 \%$, as assumed by tag return

126 studies of similar fisheries (Latour et al. 2001; Bacheler et al. 2009). When called by an angler

127 or fisher, we asked if the striped bass was commercially or recreationally caught, kept or

128 released, as well as the location and date of capture. Anglers and fishers were required to send

129 the cut tag to NCSU to receive the $\$ 100$ reward and were sent any tagging and migration

130 information about the reported striped bass.

131 Sonic tags were continuously monitored throughout the study period by stationary

132 receivers (Vemco VR2s) in the AS-RR system (Fig. 2). In addition, four of our striped bass

133 (558-609 mm TL) were detected in the Pamlico Sound system (Tim Ellis, NCSU) and all large

134 females (i.e., $\geq 900 \mathrm{~mm} \mathrm{TL}$ ) were detected by VR2s along the Atlantic Coast as far north as

135 Massachusetts (i.e., Virginia, Delaware, New York and Massachusetts; Keith Dunton, Stony

136 Brook University; Dewayne Fox, Delaware State University; Benjamin Gahagan and William 
137 Hoffman, Massachusetts Division of Marine Fisheries; Mary-Jane James-Pirri, University of 138 Rhode Island; and Carter Watterson, U.S. Department of the Navy). We also conducted 139 manual tracking (i.e., actively searching an area for an acoustically tagged fish) in the AS-RR 140 system to identify mortality associated with tagging and natural mortality. Mortality from tag 141 implantation surgery was assumed when an individual was continuously detected by manual 142 tracking in the same location within the month of tagging; these fish were removed from 143 analysis. Natural mortality was assumed when an individual was continuously found in one 144 area, but after the month of tagging and in a new location, suggesting active movement before 145 dying (Hightower et al. 2001).

For low reward ( $\$ 5$ or a hat) and PIT tagging, striped bass were collected by boat electrofishing at Weldon (Fig. 2), March-May, 2011-2013, measured for TL, examined for an external tag and scanned for a PIT tag. Detected PIT tags were recorded. If an internal anchor tag was observed, we recorded if it was readable, unreadable, or cut (due to catch and release fishing). This information was used to assess tag loss for both PIT and internal anchor tags. If no tag was present, a small incision $(<1 \mathrm{~cm})$ was made on the left side below the musculature and a PIT tag was inserted into the body cavity followed by a low reward internal anchor tag. Additional striped bass were tagged in 2011 in the Roanoke River at river kilometer 64 with only a PIT tag (Hughes and Hightower 2015). In total, we incorporated 3752 PIT-tagged individuals and 3933 low reward-tagged individuals into analysis (122 of each tag type were $\geq 900 \mathrm{~mm} \mathrm{TL}$ at tagging). Scales were also collected from striped bass on the spawning grounds, 2011-2013, 157 and assigned an age by McCargo and Dockendorf (2012; 2013; 2014); these data were used in 158 the catch-at-age submodel. Biologists scanned for PIT tags with a hand held detector while sampling harvest in the 160 Roanoke River recreational fishery, March to April 2012-2013, and in the Albemarle Sound 161 recreational and commercial fisheries, October to April 2011-2013; these months corresponded 162 to seasonal periods of legal harvest for striped bass in the AS-RR system. Scanning for PIT 
163

164

165

166

167 168

tags was conducted at least four times per week during creel surveys (for recreational harvest) and fish house sampling (for commercial harvest). The total number of striped bass scanned each month and any PIT tag numbers detected were recorded. Low reward internal anchor tags could be returned from any fishery and included information on date, location, and capture type (i.e., commercial or recreational) and whether the striped bass was harvested or released.

\section{Integrated survival and run size abundance model for resident striped bass}

We developed separate integrated models for legal but small (i.e., 458-899 mm TL) and large (i.e., $\geq 900 \mathrm{~mm} \mathrm{TL}$ ) striped bass due to drastic differences in life history and harvest patterns. Specifically, all large females tagged with an acoustic tag (939-1146 mm TL) spent approximately 11 months in the Atlantic Ocean, returning to the AS-RR only during the spawning run (Callihan et al. 2015). In contrast, smaller (445-873 mm TL) telemetered striped bass in the AS-RR stock were not detected in oceanic waters. Also, small striped bass were not reported as harvest from the Atlantic Ocean, whereas those $900 \mathrm{~mm}$ TL or larger at tagging were almost exclusively harvested from marine waters. Individuals $458-899 \mathrm{~mm}$ TL at tagging are referred to as "resident" and those $\geq 900 \mathrm{~mm}$ TL and larger are referred to as "anadromous".

\section{Multistate submodel for resident striped bass}

To estimate mortality rates, a capture history $\left(\boldsymbol{Y}_{\boldsymbol{i}, \boldsymbol{t}}\right)$ for each included resident striped bass $(i=1,2, \ldots, 103)$ tagged with an acoustic and high reward tag in each month $(t=$ $1,2, \ldots, 33$; March 2011 to October 2013) was produced using information from detections on VR2s, detections by manual tracking, and returns of high reward external tags. Capture histories $\left(\boldsymbol{Y}_{i, t}\right)$ were analyzed using a state-space multistate capture-recapture ("Multistate") model (Fig.1). Similar multistate models with live detections and dead recoveries have been used for multiple species (Kendall et al. 2006; Bischof et al. 2009; Duriez et al. 2009; Kerns et 
188

189

190

191

al. 2016). State-space models have two processes, the state process (i.e., an individual's estimated "true" state) and the observation process (i.e., what was actually observed), modeled by separate categorical distributions in the integrated likelihood.

\section{State process}

For our multistate model, individuals were estimated to be in one of nine true states as a function of survival status (e.g., alive or dead by a specific fishery) and status of the high reward tag (i.e., intact or cut/lost). The true state $\left(\boldsymbol{Q}_{\boldsymbol{i}, t}\right)$ of individual $i$ in month $t$ was estimated using a categorical distribution based on the individual's estimated true state in month $t-1\left(\boldsymbol{Q}_{\boldsymbol{i}, \boldsymbol{t}-\mathbf{1}}\right)$ and the probability of transition $(\boldsymbol{\Omega})$ to other true states (Kéry and Schaub 2012; equations for transition probabilities are on Fig. 1 Inset):

(1) $\boldsymbol{Q}_{\boldsymbol{i}, \boldsymbol{t}} \sim$ Categorical $\left(\boldsymbol{\Omega}_{\left.\boldsymbol{Q}_{i, t-1,1,2, \ldots, \mathbf{9}}\right)}\right.$

The nine estimated true states are (Fig. 1 Inset): 1) alive with a high reward tag; 2) reported harvest by the Albemarle Sound commercial fishery sector; 3 ) reported harvest by the Roanoke River recreational fishery sector; 4) reported harvest by the Albemarle Sound recreational fishery sector; 5) reported harvest by combined recreational and commercial fishing in the Pamlico fishery sector; 6) reported catch in the catch-and-release (removal of the high reward tag, but release of the fish) fishery sector; 7) natural mortality; 8) alive without a high reward tag (i.e., tag was cut or lost); and 9) undetermined death (i.e., mortality without a high reward tag). Striped bass could be alive and detected on a VR2 with or without a high reward external tag. To estimate rates of fishing mortality, natural mortality, and catch and release, Jiang et al. (2007) developed a tag return model that assessed tag removal as distinguished from fish death, which is calculated indirectly. Since we also have removal of high reward tags via harvest, catch and release, and tag loss (as opposed to just harvest), we used the Jiang et al. (2007) model to estimate transition probabilities and mortality rates. Total monthly instantaneous removal of high reward tags $\left(T_{t}\right)$ was calculated as a function of monthly fishing 
213 rates $\left(\boldsymbol{F}_{t, s=1,2, \ldots, \mathbf{5}}\right)$ from five fishery sectors $(s=1,2, \ldots 5)$, monthly natural mortality $\left(M_{q}\right)$ estimated 214 quarterly $(q=1,2,3,4)$, and a monthly rate of internal anchor tag retention $(I)$ :

$$
T_{t}=\sum_{s=1}^{5} \boldsymbol{F}_{t, \boldsymbol{s}}+M_{q}+\log (I)
$$

215 We estimated instantaneous monthly tag removal rates for five fishery sectors: commercial

216 fishing in Albemarle Sound $\left(F_{t, s=1}\right)$; recreational fishing in the Roanoke River $\left(F_{t, s=2}\right)$;

217 recreational fishing in the Albemarle Sound $\left(F_{t, s=3}\right)$; fishing in the Pamlico system $\left(F_{t, s=4}\right)$; and 218 catch and release fishing $\left(F_{t, s=5}\right)$. Monthly natural mortality $\left(M_{q}\right)$ was estimated quarterly

219 (March-May, June-August, September-November, and December-February) since unique

220 monthly estimates were imprecise and quarterly estimates appeared to capture seasonal

221 variability (See Results). A monthly internal anchor tag retention rate $(I)$ was estimated by the

222 recapture of striped bass tagged with both a PIT and an internal anchor tag after time at large

223 using a binomial likelihood:

224

$$
C_{g}^{I A} \sim \operatorname{Binomial}\left(I^{\wedge G}, N_{g}^{I A}\right)
$$

$225 \quad C_{g}^{I A}$ was the number of striped bass recaptured with a readable internal anchor tag after being 226 at large for $G$ months $(G=1,2,12,13,14,24,25)$, indexed as, $g=1,2, \ldots, 7)$ and $N_{g}^{I A}$ was the total 227 number of striped bass known to previously have had an internal anchor tag (i.e., known from its 228 PIT tag) recaptured after being at large for $G$ months. Internal anchor tag loss was considered 229 independent of PIT tag loss and loss of both tags was not addressed, but would be minimal. To estimate monthly instantaneous mortality $\left(Z_{t}\right)$ for resident striped bass (as opposed 231 to removal of tags), we needed to account for the monthly instantaneous rate of mortality 232 associated with catch and release (Kerns et al. 2012) or the catch and release mortality rate $233\left(F^{C R}\right)$ :

$$
Z_{t}=\sum_{s=1}^{4} \boldsymbol{F}_{\boldsymbol{t}, \boldsymbol{s}}+F^{C R}+M_{q}
$$


234 For striped bass, the probability of death associated with catch and release increases with 235 increasing water temperature (Nelson 1998; Bettinger et al. 2005; Millard et al. 2005). Due to 236 the small sample size in our study (only 1 of 12 fish caught and released died), we did not use 237 our data to directly estimate $F^{C R}{ }_{t}$. Instead, we used data in Nelson's (1998) hooking mortality 238 study of striped bass in the Roanoke River to estimate the probability of death associated with a 239 catch and release event as a function of water temperature using logistic regression:

$$
C_{k}^{C R D} \sim \operatorname{Binomial}\left(\psi_{k}, N_{k}^{C R D}\right)
$$

241 The number of individuals that died $\left(C^{C R D}{ }_{k}\right)$ in each experimental sample $(k=1,2, \ldots 5)$ in the 242 Nelson (1998) study was a function of the total number of striped bass caught for that specific 243 experimental sample $\left(N^{C R D}\right)$ and the probability of death due to catch and release $\left(\psi_{k}\right)$ during 244 the sample, which was evaluated as a function of water temperature. Water temperature during 245 samples in the Nelson (1998) study was recorded to range from 16.0 to $23.5^{\circ} \mathrm{C}$. The logit link 246 was used to evaluate $\psi_{k}$ as a function of water temperature during the sample $\left(W_{k}\right)$ :

$$
\operatorname{Logit}\left(\psi_{k}\right)=\beta_{1}+\beta_{2} W_{k}
$$
where $\beta_{1}+\beta_{2}$ are the intercept and slope coefficients, respectively. Thus, the mortality rate associated with catch and release fishing (i.e., $F^{C R}{ }_{t}$ ) was estimated by the rate of catch and fishing (i.e., $F_{t, s=5}$ ) and the logistic function for catch and release mortality as a function of temperature using average monthly water temperature $\left(W_{t}\right)$ at the USGS gauging station at Halifax in the Roanoke River (range from 8.3 to $30.0^{\circ} \mathrm{C}$ during the study):

$$
F_{t}^{C R}=F_{t, s=5} \exp \left(\beta_{1}+\beta_{2} W_{t}\right) /\left(1+\exp \left(\beta_{1}+\beta_{2} W_{t}\right)\right)
$$
and total instantaneous natural mortality $(M)$ were calculated. Two annual rates of fishing (all

255 fisheries combined), natural, and total mortality were calculated (May 2011 - April 2012 and May 2562012 - April 2013). Estimates from both years were used to calculate study-wide rates for $Z$ and $257 M$ : 


$$
\begin{gathered}
Z=\sum_{\text {May } 2011}^{\text {April } 2012} \frac{Z_{t}}{2}+\sum_{\text {May } 2012}^{\text {April } 2013} \frac{Z_{t}}{2} \\
M=\sum_{\text {May } 2011}^{\text {April } 2012} \frac{M_{q}}{2}+\sum_{\text {May } 2012}^{\text {April } 2013} \frac{M_{q}}{2}
\end{gathered}
$$

\section{Observation process}

The observation process in the multistate model (Fig. 1) links an individual's true state to what is observed, accounting for less than $100 \%$ detection of live individuals or deaths. What is observed $\left(\boldsymbol{Y}_{\boldsymbol{i}, \boldsymbol{t}}\right)$ for individual $i$ in month $t$ is based on observation probabilities $(\boldsymbol{\theta})$ for the individual's estimated true state $\left(\boldsymbol{Q}_{\boldsymbol{i}, t}\right)$ in month $t$ (Kéry and Schaub 2012):

$$
\boldsymbol{Y}_{\boldsymbol{i , t}} \sim \operatorname{Categorical}\left(\boldsymbol{\theta}_{\left.\boldsymbol{Q}_{i, t}, \mathbf{1 , 2 , \ldots , \mathbf { 8 }}\right)}\right.
$$

We had eight observed states: 1) detected alive on a stationary receiver; 2) reported harvest by commercial fishing in the Albemarle Sound; 3) reported harvest by recreational fishing in the Roanoke River; 4) reported harvest by recreational fishing in the Albemarle Sound; 5) reported harvest in the Pamlico system; 6) reported catch-and-release; 7) detected natural mortality; and 8) undetected. We assumed all intact high reward tags on caught striped bass were returned and information was reported without error; thus, all fishery deaths for individuals with an intact high reward internal anchor tag in the previous month (i.e., true states $\# 2,3,4,5,6$ ) were detected with a probability of 1 as observed states \#2,3,4,5,6, respectively (Fig. 1 Inset). A reported harvest would also indicate that the fish's true state was \#1 in all previous months (Fig. 1 Inset). In contrast, after removal (i.e., cut or loss) of the internal anchor tag, any death was considered undetectable (i.e., true state \#9 has observed state \#8 with a probability of 1; Fig. 1 Inset). The remaining true states $(\# 1,7,8)$ could either be detected or undetected. Monthly detection probabilities $\left(p^{L I V E}{ }_{t}\right)$ for live fish with (true state \#1) or without (true state \#8) an internal anchor tag were estimated in the model by the pattern of detections on stationary receivers (Fig. 1 Inset and Fig. 2). Detection of natural mortality (true state \#7) was rare; thus, we only estimated an 
279 overall mean detection probability $\left(p^{N M}\right)$. As described by Hightower et al. (2001), we assumed 280 that an individual found in the same location on multiple events without report from an angler or 281 fisher died of natural mortality and still possessed an intact high reward internal anchor tag at 282 the time of death (i.e., the true state in the month before death was \#1; Fig. 1 Inset). We 283 assumed no sonic-tag loss.

Tag detection submodel for resident striped bass with an internal PIT tag We constructed matrices of detections of PIT tags $\left(X_{c, t, s}^{P I T}\right)$ by release cohort $(c=$ $1,2, \ldots, 5)$, month $(t=1,2, \ldots, 33)$, and scanned fishery sector $(s=1,2,3)$. Although tagging was completed weekly in April 2011, May 2011, April 2012, May 2012, and April 2013, tags were collapsed into monthly intervals (i.e., five monthly cohorts) for analysis. Detections of PIT tags were analyzed by an instantaneous rates formulation of the Brownie tag return model (Brownie et al. 1985; Hoenig et al. 1998a). PIT tags were detected by scanning a known or estimated fraction of harvest from three of the five fishery sectors $(s)$ : commercial harvest in Albemarle Sound ( $s=1)$; recreational harvest in the Roanoke River $(s=2)$; and recreational 294 harvest in Albemarle Sound $(s=3)$. We accounted for the fraction of harvest scanned for PIT 295 tags and assumed all PIT tags scanned were detected. Detected PIT tags (i.e., $\boldsymbol{X}_{\boldsymbol{c}, \boldsymbol{t}, \boldsymbol{s}}^{\text {) }}$ ) were 296 assumed to be from a multinomial distribution with an expected detection probability matrix $297\left(P_{c, t, s}^{P I T}\right)$ based on the number of individuals released in each cohort $\left(R_{c}^{P I T} ;\right.$ Fig. 1):

$$
\boldsymbol{X}_{c, t, s}^{P I T} \sim \operatorname{Multinomial}\left(\boldsymbol{P}^{P I T}{ }_{c, t, s}, R^{P I T}{ }_{c}\right)
$$

299 The probability of detecting a PIT tag (i.e., $P_{c, t, s}^{P I T}$ ) was a function of mortality rates and 300 multiple nuisance parameters:

$$
\boldsymbol{P}_{\boldsymbol{c}, \boldsymbol{t}, \boldsymbol{s}}^{\boldsymbol{P I T}}=\boldsymbol{S}_{\boldsymbol{t}, \boldsymbol{s}} \delta \boldsymbol{\phi}^{\boldsymbol{P I T}}{ }_{\boldsymbol{c}, \boldsymbol{t}} \frac{\boldsymbol{F}_{\boldsymbol{t}, \boldsymbol{s}}}{Z_{t}}\left(1-\exp \left(-Z_{t}\right)\right)
$$


301 where $S_{t, s}$ is the proportion of harvested PIT tags scanned during month $t$ from sector $s, \delta$ is the 302 proportion of PIT tags retained, $\phi_{c, t}^{P I T}$ is cumulative survival for individuals within cohort $c$ from 303 tagging until month $t, \frac{F_{t, s}}{Z_{t}}$ is the proportion of total instantaneous mortality $\left(Z_{t}\right)$ during month $304 t$ attributed to fishery sector $s$, and $\left(1-\exp \left(-Z_{t}\right)\right)$ is total proportion of mortality for month $t$. 305 The sampling process for the proportion of harvested PIT tags scanned, by sector and month $306\left(S_{t, s}\right)$, was represented using a binomial likelihood, with the total number of striped bass 307 examined for PIT tags $\left(\boldsymbol{E}_{t, s}\right)$ and total harvest $\left(\boldsymbol{H}_{t, s}\right)$ :

$$
\boldsymbol{E}_{\boldsymbol{t}, \boldsymbol{s}} \sim \operatorname{Binomial}\left(\boldsymbol{S}_{t, \boldsymbol{s}}, \boldsymbol{H}_{t, s}\right)
$$

Harvest for the Albemarle commercial striped bass fishery must be reported daily to the North

310 Carolina Division of Marine Fisheries; harvest in the Albemarle Sound recreational fishery and

311 the Roanoke River recreational fishery are estimated by creel surveys conducted by the North

312 Carolina Division of Marine Fisheries and the North Carolina Wildlife Resources Commission.

313 Unlike for internal anchor tags, PIT tag loss did not appear to increase over time; thus, it was

314 assumed that an initial tag loss value was appropriate; the PIT tag retention probability $(\delta)$ was

315 estimated by a binomial likelihood, with the number of fish with PIT tags $\left(C^{P I T}\right)$ and the number 316 of fish known to have previously had a PIT tag from a present internal anchor tag $\left(N^{P I T}\right)$ :

$$
C^{P I T} \sim \operatorname{Binomial}\left(\delta, N^{P I T}\right)
$$

318 For the month of release, an additional parameter was included to account for multiple releases 319 within the month. The proportion of the newly released cohort available to the Roanoke River 320 recreational fishery $\left(\mu^{P I T}{ }_{c}\right)$ was estimated using a normal distribution (with standard deviation $\left.321 \sigma^{P I T}{ }_{c}\right)$ based on the proportion of the month available $\left(\boldsymbol{V}^{P I T}{ }_{n, c}\right)$ for all individuals in that cohort:

$$
\boldsymbol{V}_{n, \boldsymbol{c}}^{P I T} \sim \operatorname{Normal}\left(\mu_{c}^{P I T}{ }, \sigma_{c}^{P I T}\right)
$$

322 Also, while individuals could be (and sometimes were) caught in the Roanoke River on the day 323 they were tagged, they were not immediately available to fisheries elsewhere (i.e., Albemarle 
324 Sound and the Pamlico system) due to physical distance, so a parameter was included $(\gamma)$ to 325 account for spatial non-mixing during the month of release for fisheries outside the Roanoke 326 River (Hoenig et al. 1998b; Waterhouse and Hoenig 2011).

Tag return submodel for resident striped bass with a low reward external tag Similar to PIT tags, the number of returns of low reward tags from each cohort $(c=$ $1,2, \ldots 6)$, in each month $(t=1,2, \ldots 33)$ from each fishery sector $(s=1,2, \ldots, 5)$ was recorded in a matrix $\left(X_{c, t, s}^{L R T}\right)$; however, unlike for PIT tags, low reward tags could be and were returned from all five fishery sectors: commercial harvest in Albemarle Sound $(s=1)$; recreational harvest in the Roanoke River $(s=2)$; recreational harvest in Albemarle Sound $(s=3)$; harvest in the Pamlico system $(s=4)$; and catch and release fishing $(s=5)$. Similar to PIT tags, low reward tags put out weekly were collapsed into monthly cohorts for the months of April 2011, May 2011, April 2012, May 2012, April 2013, but also May 2013 (i.e., 6 cohorts). Parameter estimates were obtained using a multinomial likelihood:

$$
\boldsymbol{X}_{\boldsymbol{c}, \boldsymbol{t}, \boldsymbol{s}}^{\boldsymbol{L} \boldsymbol{T} \boldsymbol{M}} \sim \operatorname{Multinomial}\left(\boldsymbol{P}_{\boldsymbol{c}, \boldsymbol{t}, \boldsymbol{s}}^{L R T}, R_{c}^{L R T}\right)
$$

The expected number in each matrix cell for each cohort $(c)$, month $(t)$, and fishery sector $(s)$ was the product of the total number of individuals released in each cohort $\left(R^{L R T}{ }_{c}\right)$ and return 341 probability $\left(P_{c, t, s}^{L R T}\right)$ which are a function of mortality rates and nuisance parameters (Fig. 1):

$$
\boldsymbol{P}_{\boldsymbol{c}, \boldsymbol{t}, \boldsymbol{s}}^{\boldsymbol{L} \boldsymbol{R} \boldsymbol{T}}=I_{t} \lambda_{*} \boldsymbol{\phi}_{\boldsymbol{c}, \boldsymbol{t}}^{\boldsymbol{L R T}} \frac{\boldsymbol{F}_{\boldsymbol{t}, \boldsymbol{s}}}{T_{t}}\left(1-\exp \left(-T_{t}\right)\right)
$$

$342 I_{t}$ is the cumulative internal anchor tag retention from tagging to month $t, \lambda_{*}$ is the reporting rate 343 of low reward internal anchor tags, $\phi_{c, t}^{L R T}$ is cumulative survival for cohort $c$ from tagging to

344 month $t, \frac{\boldsymbol{F}_{t, s}}{T_{t}}$ is the proportion of total instantaneous removal of internal anchor tags $\left(T_{t}\right)$ in month $345 t$ attributed to fishery sector $s$, and $\left(1-\exp \left(-T_{t}\right)\right)$ is total proportion of low reward tags removed 346 in month $t$. Unlike for high reward tags which we assumed were always reported, we estimated 
347 two reporting rates for low reward internal anchor tags, one for the commercial fishery in

348 Albemarle Sound $\left(\lambda_{1}\right)$ and one for all other fisheries $\left(\lambda_{2}\right)$, which were predominantly

349 recreational. Similar to PIT matrices, nuisance parameters were included to account for release

350 timing and spatial non-mixing during the month of release for each cohort (Fig 1).

Catch-at-age submodel for resident striped bass (2012; 2013; 2014) were used in a catch curve likelihood model (i.e., linear regression of the natural log of catch by estimated age) to contribute to the estimate of study-wide annual instantaneous total mortality (i.e., $Z$ ) in the integrated model (i.e., equation (8); Fig. 1). We assumed a linear decline in catch-at-age for striped bass ages 3-9 (Fig. 3). These age classes generally correspond to the sizes of striped bass we considered resident (i.e., ages 3-9 were generally 458-900 mm TL; McCargo and Dockendorf 2012; 2013; 2014). Expected values $\left(\boldsymbol{\mu}_{a, y}^{A G E}\right)$ for each included age $(a=3,4, \ldots, 9)$ and spawning run $(y=1,2,3)$ were estimated by a normal distribution with standard deviation $\left(\sigma^{A G E}\right)$ :

$$
\boldsymbol{N}_{a, y}^{A G E} \sim \operatorname{Normal}\left(\boldsymbol{\mu}_{a, y}^{A G E}, \sigma^{A G E}\right)
$$

362 Thus, $\boldsymbol{\mu}_{a, y}^{A G E}$ was estimated by linear regression with an intercept $(\alpha)$ and a slope equal to 363 study-wide annual total instantaneous fishing mortality (i.e., $Z$; equation (8)):

$$
\boldsymbol{\mu}_{\boldsymbol{a}, \boldsymbol{y}}^{A G E}=\alpha-Z
$$

Roanoke River striped bass run size abundance estimates three spawning runs $(2011-2013$, indexed as $y=1,2,3)$ to produce total $\left(A_{y, 1}\right)$ and harvestable

$368\left(A_{y, 2}\right)$ run size abundance estimates (Fig. 1). Total run sizes were estimated by evaluating total catch (i.e., harvest and catch and release), whereas harvestable run size estimates were 
370

371

372

373

374

375

376

377

378

379

380

381

382

383

384

evaluated using information on harvest only. Total run size estimates for each spawning run were produced by dividing total catch in the Roanoke River during that spawning run (i.e., estimated harvest and catch and release in the Roanoke River) by exploitation of tags in the Roanoke River during that spawning run (i.e., estimated fraction of total tag removal due to harvest in the Roanoke River and catch and release, in March to May of that year). Expected total catch was estimated for each spawning run from a normal distribution with expected values $\left(H_{y, 1}\right)$ and error $\left(\sigma_{y, 1}^{H A R}\right)$ from McCargo and Dockendorf $(2012 ; 2013 ; 2014)$. Exploitation of tags in the Roanoke River during the spawning run was estimated as:

$$
\left(1-\exp \left(T_{y}\right)\right)\left(F_{y, s=2}+F_{y, s=5}\right) / T_{y}
$$

where $F_{y, s=2}$ is the sum of recreational fishing mortality in the Roanoke River during the run, $F_{y, s=5}$ is the sum of the catch and release fishing rate during the spawning run, and $T_{y}$ is instantaneous removal of tags (described above) during the spawning run in each year. We similarly estimated the harvestable run size by dividing a similar estimate of total harvest with error (i.e., $H_{y, 2}$ and $\sigma_{y, 2}^{H A R}$ ) in the Roanoke River by exploitation due only to harvest:

$$
\left(1-\exp \left(T_{y}\right)\right)\left(F_{y, s=2}\right) / T_{y}
$$

\section{Model analyses}

All models in this study were evaluated by Bayesian methods with JAGS software (Plummer 2003) called from R statistical analysis software (R Core Team 2013). Prior distributions for the integrated model for resident striped bass are in Table 2. For integrated models (i.e., resident and anadromous), posterior distributions were from three chains and 500000 iterations after a burn-in of 100 000, which resulted in Rhat scores of less than 1.03 for all parameters. Model convergence is often assumed when Rhat scores for all parameters are less than 1.1 (Gelman and Hill 2007; Kéry and Schaub 2012). The joint likelihood in an integrated model is the product of all individual likelihoods (Fig. 1). In JAGS, the joint likelihood 
393 is defined implicitly; thus, multiple data sources can be included to estimate common

394 parameters with appropriate variance (Rhodes et al. 2011; Kéry and Schaub 2012). To

395 evaluate the relative contribution of tag returns to the overall analysis for resident striped bass,

396 we compared mortality rate estimates from the integrated model to those from a multistate

397 telemetry model alone (Fig.1). For all models, we report the median of the posterior distribution

398 as a measure of central tendency (i.e., as the "estimate") and $2.5 \%$ and $97.5 \%$ values in the

399 posterior distribution as $95 \%$ credible intervals.

\section{Integrated survival model and analysis for anadromous striped bass} sonic and high reward tagged females and 122 low and PIT tagged males and females), we only estimated fishing and natural mortality for the AS-RR system and for the Atlantic Ocean. Similar to Rudd et al. (2014), periods were based on area (i.e., rather than month); the first period in a year represented the approximately month-long spawning migration in the AS-RR system, whereas the second period represented 11 months in the Atlantic Ocean, as described by Callihan et al. (2015). Since we did not sample any ocean fishery for PIT tags and only one

411 reporting rate would be generally expected given estimated reporting rates for resident striped

412 bass (See Results). We assumed internal anchor tag retention was not impacted by fish size;

413 thus, we used the same data and likelihood model to estimate the rate for anadromous fish as

414 used for residents (equation (3)). We did not include a non-mixing parameter. Since stationary

415 receiver coverage was very high in the Roanoke River and few fish appeared to be missed

416 during the Atlantic Ocean residence (i.e. 11 months), we estimated one mean detection

417 probability for all periods using the same prior distribution as used for resident striped bass (i.e.,

418 a uniform from 0 to 1 ). We did not detect any natural mortality; thus, all natural mortality was 
419

420

421

422

423

424

425

426

427

428

429

430

431

432

433

434

435

436

437

438

439

440

assessed within the model by the cessation of detections on stationary receivers. We had no indication of catch and release; thus, any mortality from it was assumed to be negligible. We estimated average monthly rates of fishing and natural mortality for anadromous striped bass in the Atlantic Ocean $\left(f^{O C E A N}\right.$ and $\left.m^{O C E A N}\right)$ and the AS-RR system $\left(f^{A S R R}\right.$ and $\left.m^{A S R R}\right)$ using the same prior distributions as used for monthly fishing mortality rates for resident striped bass (i.e., a uniform from -10 to 1 on a natural log scale). We calculated average annual rates of fishing $\left(F^{A N A}\right)$ natural $\left(M^{A N A}\right)$, and total $\left(Z^{A N A}\right)$ instantaneous mortality for anadromous striped bass based on the amount of time spent in each area (i.e., 11 months in the Atlantic Ocean and 1 month in the AS-RR system; Callihan et al. 2015):

$$
\begin{gathered}
F^{A N A}=11\left(f^{\text {OCEAN }}\right)+f^{A S R R} \\
M^{A N A}=11\left(m^{O C E A N}\right)+m^{A S R R} \\
Z^{A N A}=F^{A N A}+M^{A N A}
\end{gathered}
$$

\section{Simulation to evaluate an integrated tagging model}

By simulation ( $\mathrm{n}=500$ replicates), we examined monthly and annual fishing and natural mortality rates estimated by a multistate model of passive detections of sonic-tags with return of high reward tags ("Multistate"), as compared to an integrated model that also included returns of low reward tags ("Integrated"). Monthly estimates identify seasonal patterns in mortality to inform biology and improve management, whereas annual estimates are used directly for stock assessment. Capture histories and tag return matrices were simulated using median posterior

estimates of $F_{t}, M_{e}$, and $p_{t}^{L I V E}$ from our final integrated model for resident AS-RR striped bass (Table 3). $F_{t}$ was equal to the sum of all fishing mortality rates (i.e., $\boldsymbol{F}_{\boldsymbol{t}, \boldsymbol{s}=\mathbf{1 , 2 , 3 , 4}}$ and $F^{C R}$ ). An average reporting rate (from our posterior estimates) for commercial and recreational fisheries in the AS-RR system was used in integrated model simulations (i.e., 0.40). There were 15 simulated periods (i.e., months) corresponding to April 2011 to June 2012. Datasets were 
441 simulated in Program $\mathrm{R}$ and mortality rates for simulated datasets were estimated in JAGS.

442 Prior distributions for parameters in the simulated models were the same as those used in the

443 integrated model for resident striped bass (Table 2). Simulated datasets were evaluated with a

444 burn-in of 1000 and iteration increments of 1000 until convergence was reached, as assumed

445 when Rhat scores for all estimated parameters were less than 1.1 (Gelman and Hill 2007; Kéry 446 and Schaub 2012).

447 The multistate and integrated models evaluated by simulation were simplified as

448 compared to the resident striped models to be generally practical for other fish populations and

449 studies. Simplifications included estimating only one rate of fishing mortality (as opposed to

450 fishing mortality by sector), and assuming no tag loss, no non-mixing, no catch and release

451 fishing and no manual searches. A multistate model was used to analyze simulated capture

452 histories of striped bass each tagged with a sonic and a high reward tag released before the

453 start of month one. There were three true states: 1) alive with both tags; 2) harvested; and 3)

454 natural death. There were three observed states: 1) detected alive; 2) returned high reward tag

455 indicating harvest; and 3) not detected. High reward tags were assumed to be returned with a

456 probability of 1 . Live fish were detected with a probability of $p^{L I V E}{ }_{t}$, but we assumed no manual

457 searching so there was no detection of natural mortality. For the integrated model, an

458 instantaneous rates formulation of a Brownie tag return model was used to analyze simulated

459 low reward tag return matrices (Brownie et al. 1985; Hoenig et al. 1998a).

460 To examine if multistate and integrated models appropriately assess monthly and

461 seasonal patterns in mortality rates, we evaluated 100 fish tagged with both a sonic and a high

462 reward tag and 1000 fish tagged with a low reward tag. These are similar to the sample sizes

463 we had for our striped bass study and thus help evaluate the expected value of our results, but

464 are also potentially reasonable sample sizes for similar studies on other species. Tagged fish

465 were released before the start of the simulation. Although unlikely to affect model results, one

466 low reward tagged individual was released in all other months for coding purposes. We 
467

468

469

470

471

472

473

474

estimated monthly rates of fishing mortality, and both monthly and seasonal patterns for natural mortality rates. Estimates from the final month (i.e., simulated period 15) were not examined due to confounding between the final estimate of natural mortality and detection probability. We visually assessed seasonal patterns in fishing and natural mortality rates identified by the multistate and integrated models.

Since annual rates are used in stock assessment, we also examined impacts of sample size on bias, accuracy, and precision of annual fishing $\left(F^{S I M}\right)$ and natural $\left(M^{S I M}\right)$ mortality rates. Estimates of $F^{S I M}$ and $M^{S I M}$ were calculated in JAGS as the sum of rates from months 1-12:

$$
\begin{aligned}
& M^{S I M}=\sum_{t=1}^{12} M^{S I M}{ }_{t} \\
& F^{S I M}=\sum_{t=1}^{12} F^{S I M}{ }_{t}
\end{aligned}
$$

475 We ran simulations assuming 50,100 , or 200 sonic and high reward tagged fish in the

476 multistate component and 0,1000, or 2000 fish in the low reward tag return component.

477 These sample sizes correspond generally to what may be practical in future studies and

478 illustrate the potential value of results from our study of striped bass. Simulations with 0 fish 479 tagged for the low reward tag return component are an evaluation of a multistate only model. We assessed annual estimates for different simulated sample sizes visually and by

481 calculations. We quantified percent bias for each simulation by relative error (RE; calculated as 482 ((estimate-True)/True $)^{\star} 100 ;$ Vandergroot and Brendan 2015). We quantified percent accuracy 483 of each simulation by absolute relative error (ARE; calculated as absolute value of ((estimate484 True)/True)*100; Wilberg and Bence 2006). We plotted the medians (i.e., MRE and MARE) and 485 the $1^{\text {st }}$ and $3^{\text {rd }}$ quantiles from our simulations to evaluate percent bias (MRE close to zero 486 suggests lack of bias) and percent accuracy (i.e., MARE close to zero suggests accuracy) for 487 different sample sizes. Finally, we also assessed precision by the percent coefficient of 488 variation $\left(\mathrm{CV}=(\right.$ standard deviation of all estimates $\left.) /(\text { mean of all estimates })^{\star} 100\right)$. 


\section{Results}

\section{Integrated survival and run size abundance model for resident striped bass}

Of the 103 sonic and high reward tagged residents included in analysis, seven (6.8\%) were reported as harvest in the commercial fishery in Albemarle Sound, two (1.9\%) were

494 reported as recreational harvest in the Albemarle Sound, two (1.9\%) were reported as

495 recreational harvest in the Pamlico system, five (4.9\%) were reported as recreational harvest in 496 the Roanoke River, and $12(11.7 \%)$ were reported as catch and release (Table 1). No striped 497 bass less than $900 \mathrm{~mm}$ TL were reported as caught in any other area. Detection patterns on 498 stationary receivers corroborated angler and fisher reports both spatially and temporally. We 499 detected one instance of mortality after catch and release; it occurred in mid-June at the mouth 500 of the Roanoke River. Within the integrated model, mortality due to catch and release was 501 estimated by logistic regression as a function of temperature with an intercept (i.e., $\beta_{1}$ ) 502 estimated at -8.60 (95\%: $-13.27--4.67$ ) and a slope (i.e., $\beta_{2}$ ) estimated at 0.31 (95\%: $0.12-$ 503 0.52), illustrating an increase in catch and release mortality, as temperature increased.

We scanned $24.5 \%$ of the commercial harvest in Albemarle Sound and detected 41 PIT 505 tags (Table 1). Lower percentages of the recreational harvest were estimated to have been 506 scanned (8.2\% in the Roanoke River and 5.3\% in the Albemarle Sound) due to the dispersed 507 nature of those fisheries in time and space. We detected 10 PIT tags in the Roanoke River 508 recreational fishery and only one in the Albemarle Sound recreational fishery. Low reward tags 509 were returned from commercial $(n=37)$ and recreational $(n=45)$ fisheries in the Albemarle 510 Sound, the recreational fishery in the Roanoke River $(n=65)$, fisheries in the Pamlico Sound 511 system $(n=4)$, and as a result of catch and release $(n=144)$. Low reward tags from striped bass $512458-899 \mathrm{~mm}$ TL were not returned from any other locations. Non-mixing (i.e., $\gamma$ ) outside of the 513 Roanoke River during the month of release was estimated in the integrated model as 0.11 514 (95\%: $0.014-0.40)$. 
PIT tags were retained in 71 of 74 striped bass $(\delta=0.94,95 \%: 0.86-0.98)$. Internal

516

517

518

519

520

521

522

523

524

525

526

527

528

529

530

531

532

533

534

535

536

537

538

539

anchor tags were retained and readable for at least 25 months in 52 of 61 recaptured individuals $(I=0.94,95 \%: 0.93-0.96)$. Reporting rate was slightly lower for the Albemarle Sound commercial fishery $\left(\lambda_{1}=0.36,95 \%: 0.23-0.58\right)$ than for the combined recreational fisheries $\left(\lambda_{2}\right.$ $=0.43,95 \%: 0.32-0.59)$, although $95 \%$ credible intervals overlapped.

Monthly detection probability estimates (i.e., $p_{t}^{L I V E}$ ) for resident striped bass were 0.38

to 0.99 . Detection was highest in the spring when most sonic-tagged striped bass were in the Roanoke River, since few detected striped bass were missed at even one receiver during the spawning run (Fig. 2). Detection probability was lowest during fall, when individuals were dispersed throughout the Albemarle Sound. Detection probability for natural mortality (i.e., $p^{N M}$ ) was $0.11(95 \%: 0.08-0.13)$.

\section{Survival for resident striped bass}

The natural log of the average number of striped bass age $3-9$ caught in the Roanoke River during spring spawning surveys generally showed a linear pattern of decline with age (Fig. 3). The pattern of decline in catch-at-age expected by the estimated intercept of the catch-atage submodel ( $\alpha=11.11,95 \%, 10.17-12.43)$ and estimated study-wide total instantaneous mortality for resident striped bass (i.e., $Z$, see below for estimate) was similar to the pattern of decline observed from scales of striped bass catch ages $3-9$. The pattern of decline was not linear (and not well represented by the integrated model expected values for residents) for striped bass below age- 3 or above age- 9 . Within the integrated model, the standard deviation for the catch-at-age submodel (i.e., $\sigma^{A G E}$ ) was 0.87 (95\%: $\left.0.60-1.38\right)$.

Fishing mortality rates estimated by the integrated model for resident striped bass, March 2011 to May 2013, were consistent with monthly periods of legal harvest (Fig. 4). Monthly rates of fishing mortality were highest in March and April during the spawning run when 
540 all fisheries were open. Catch and release was highest during the spawning period, but was

541 reported during almost all months. Catch and release mortality was low (Fig. 4). Total annual

542 instantaneous fishing mortality was 0.45 (95\%: $0.34-0.58)$ in the first year and $0.31(95 \%: 0.23$

$543-0.43)$ in the second year. Natural mortality was highest in the summer and almost non-

544 existent during the rest of the year (Fig. 4). Annual instantaneous natural mortality was 0.62

545 (95\%: $0.46-0.80)$ in the first year and $0.79(95 \%: 0.57-1.05)$ in the second year, for a study-

546 wide rate (i.e., $M$ ) of 0.70 (95\%: $0.58-0.86)$. The study-wide total annual instantaneous

547 mortality rate for resident striped bass (i.e., $Z$ ) was 1.08 (95\%: $0.94-1.28)$.

Seasonal estimates of natural mortality for striped bass $458-899 \mathrm{~mm}$ TL at tagging

produced by telemetry and high reward tag returns alone (i.e., "Multistate") were very similar in sonic and high reward tagged fish was lower as compared to earlier in the study (Table 1; Fig. natural mortality $(0.74,95 \%$ : $0.53-0.99)$, but a higher estimate of study-wide total annual

557 instantaneous mortality (1.52, 95\%: $1.22-1.90)$ than the integrated model.

\section{Roanoke River striped bass run size abundance estimates}

Roanoke River run size estimates during the study period ranged from approximately

562 (2013) to $56 \%$ (2012) of the total run in each year (Table 4). 
For striped bass at least $900 \mathrm{~mm}$ TL at tagging, two sonic and high reward-tagged

566

567

568

569

570

571

572

573

574

575

576

577

578

579

580

581

582

583

584

585

586

587

588

589

individuals were known to be harvested, one recreationally in the Atlantic Ocean off the coast of Massachusetts and the other in the Albemarle Sound commercial fishery upon entry in the ASRR system during the spawning run. Detection probability on stationary receivers in the AS-RR system and Atlantic Ocean within a period was estimated by the integrated model at 0.95 (95\%: $0.83-0.99)$. Of the 122 low reward tagged individuals, nine were reported as recreational harvest in the Atlantic Ocean off the coasts of Massachusetts, New York, and New Jersey and none were reported from any other areas. Annual instantaneous natural mortality (i.e., $M^{A N A}$ ) was estimated at 0.21 (95\%: $0.03-0.52)$, annual instantaneous fishing mortality (i.e., $F^{A N A}$ ) was estimated to be 0.23 (95\%: $0.01-0.48)$, and annual total instantaneous mortality (i.e., $Z^{A N A}$ ) was estimated at 0.45 (95\%: $0.21-0.86$. For these larger striped bass, the median estimate of monthly fishing mortality was higher in the Atlantic Ocean $\left(f^{\text {OCEAN }}=0.019,95 \%\right.$ : $0.008-0.041)$ than Albemarle Sound $\left(f^{A S R R}=0.011,95 \%: 0.000-0.059\right)$, whereas average monthly natural mortality was higher in Albemarle Sound $\left(m^{A S R R}=0.147,95 \%: 0.001-0.380\right)$, as compared to the Atlantic Ocean $\left(m^{\text {OCEAN }}=0.003,95 \%: 0.000-0.032\right)$, although $95 \%$ credible intervals were sometimes large and overlapped. For anadromous striped bass, the most substantial mortality component was natural mortality in Albemarle Sound during emigration after spawning.

\section{Simulation to evaluate an integrated tagging model}

Simulation showed that both the multistate only model and the integrated model produced estimates of monthly and annual fishing and natural mortality rates that would increase understanding of biology and be valuable for stock assessment (Figs. 5 and 6).

Monthly rates estimated by both the multistate and the integrated model identified seasonal patterns in fishing and natural mortality rates; however, the integrated model produced more 
590

591

592

593

594

595

596

597

598

599

600

601

602

603

604

605

606

607

608

609

610

611

612

613

614

615

accurate and precise estimates of monthly fishing mortality rates than the multistate only model

(Fig. 5). In addition, estimating a seasonal pattern for natural mortality produced higher accuracy and precision for natural mortality than estimating it as a monthly rate (Fig. 5).

With adequate sample size, multistate and integrated tagging models produced

unbiased, accurate, and precise estimates of annual fishing and natural mortality rates useful for stock assessment (Fig. 6). Regardless of sample size, the interquartile range for estimated mortality rates and RE values overlapped zero (Fig. 6). For all sample sizes examined, MRE values for natural mortality were slightly positive. Values of MRE for fishing mortality were slightly positive for the multistate only model, but slightly negative for the integrated model. Bias decreased and accuracy and precision increased with increasing sample size of sonic and high reward tags in the multistate component, whereas increasing the number of low reward tags in the tag return component had barely perceivable effects (Fig. 6). The MRE was below $10 \%$ for all sample sizes examined, but was only below $5 \%$ when at least 100 individuals were tagged with a sonic and high reward tag. The MARE was below $20 \%$ for all sample sizes, but was only below $10 \%$ when at least 200 individuals were tagged with a sonic and high reward tag. The CV was below $30 \%$ for all sample sizes examined, and was below $20 \%$ if at least 100 individuals were tagged with a sonic and high reward tag (Fig. 6).

\section{Discussion}

Our results show that the combination of live detections of sonic-tagged individuals on stationary receivers with reported harvest of external tags evaluated by a multistate or integrated model can provide extensive, fine-scale, high quality data on mortality rates. When fishing mortality is assumed to always be reported, the state space portion of the multistate model uses detection patterns to effectively differentiate living, but undetected fish, from natural mortality. Since state space multistate models are flexible in design and provide unbiased, accurate, and precise estimates of annual fishing and natural mortality, they could be used to 
616 improve stock assessment for multiple species (Hightower and Harris In Press). However, our

617 striped bass example illustrates how small sample sizes can result in imprecise monthly

618 estimates of mortality rates from multiple fishery sectors when a multistate only model is

619 evaluated. Low precision in monthly estimates for multiple fishery sectors is likely because few

620 individuals were caught in any one fishery sector within a month. The number of sonic-tags

621 used is limited by expense and the potential for tag transmissions to collide (i.e., multiple tags

622 transmitting at same time can result in none being detected by a stationary receiver) in areas of

623 high density. The addition of low reward tag return and PIT detection data through analysis of

624 an integrated model clarified monthly patterns in fishing mortality by sector. Tag return models

625 alone can also produce valid estimates of fishing mortality rates, as long as reporting rate is

626 effectively estimated (see Pollock et al. 1991; 2001; 2002). However, natural mortality is

627 estimated only indirectly in tag return models and seasonal patterns cannot be assessed during

628 periods without harvest (i.e., April-October in this study). In our study, low reward tags likely

629 contributed more to estimates for recreational fisheries since reporting rate was slightly higher

630 as compared to the commercial sector. In contrast, PIT tags were more helpful for estimating

631 commercial fishing mortality rates, since commercial harvest must be reported and scanning

632 harvest in fishhouses was much more efficient than scanning dispersed (both spatially and

633 temporally) recreational fisheries; thus, more commercial harvest was scanned and more PIT

634 tags were detected in the commercial fishery (Table 1).

The integrated tagging model helped us identify spatial and temporal patterns in striped bass fishing and natural mortality rates. As expected, Roanoke River recreational fishing was

637 concentrated in the early part of the spawning run. Albemarle Sound fisheries were temporally

638 dispersed, but peaked during or just before the spawning run. Catch and release did not

639 contribute substantially to mortality because water temperature during periods of high catch and

640 release rates were low (Nelson 1998; Bettinger et al. 2005; Millard et al. 2005). However, catch

641 and release may also impact population growth by altering spawning behavior. Movement 
642 patterns and spawning behavior can be evaluated by examining detection patterns on stationary

643 receivers in response to reported catch and release. Impacts of repeated catch and release of

644 a single striped bass were not evaluated, but could be important (Kerns et al. 2012).

Although natural mortality was low during most of the year, it was substantial during summer months, when water temperatures peaked in Albemarle Sound. Striped bass in poor

647 physical condition (i.e., low relative weight and high occurrence of lesions) have been observed

648 in Albemarle Sound during summer; poor condition during this period may be a result of thermal

649 stress and may be more prevalent for individuals larger than $325 \mathrm{~mm}$ TL (Haeseker et al. 1996).

650 It may be possible to use summer water temperature to predict annual natural mortality and thus

651 the status of the stock on an annual basis. A better understanding of the impacts of estuarine

652 water temperature on striped bass natural mortality would help evaluate potential impacts of 653 climate change on fish populations.

Our study suggests that larger anadromous striped bass had substantially different

655

656

657

658

659

660

661

662

663

664

665

666

667

mortality rates than residents. Annual instantaneous natural mortality for striped bass 458-899 $\mathrm{mm}$ TL was estimated at $0.70(95 \%: 0.58-0.86)$ as compared to $0.21(95 \%: 0.03-0.52)$ for larger striped bass in the population. These differences may be attributed to fish behavior. Anadromous females spent little time in Albemarle Sound, appearing to use it only as a corridor to reach spawning grounds in the Roanoke River in the spring (Callihan et al. 2015). However, these anadromous fish were estimated to experience the highest natural mortality rates in the AS-RR during emigration after spawning. Higher natural mortality in the AS-RR, compared to the Atlantic Ocean, may be a function of spawning stress, warmer water temperatures, reduced feeding, or a combination. Larger individuals may reduce thermal stress and increase food availability by migrating to northern areas of the Atlantic Ocean during non-spawning periods, especially during warm periods in their natal estuaries (Secor and Piccoli 2007; Mather et al. 2009; Callihan et al. 2014). After emigration, these anadromous striped bass are vulnerable to recreational fisheries along the Atlantic Coast. Understanding mortality rates for anadromous 
668

669

670

671

672

673

674

675

676

677

678

679

680

681

682

683

684

685

686

687

688

striped bass is essential because they likely contribute more to future year classes than younger individuals due to their higher fecundity (Boyd 2011).

Although we evaluated two size classes (i.e., above and below $900 \mathrm{~mm}$ TL), size likely impacts mortality on a finer scale. In general, juvenile fish survival increases with size, as individuals become less available to predators (Lorenzen 1996; Sogard 1997). However, natural mortality in the summer for larger, but not yet anadromous, striped bass may be higher than for smaller resident individuals (Haeseker et al. 1996). Fishing mortality is also impacted by fish size. The Roanoke River has a protective slot of 559 to $686 \mathrm{~mm}$ TL (i.e., 22-27 inches), but this size class may be more prevalent in Albemarle Sound recreational and commercial fisheries. Regardless, the natural log of catch-at-age data showed a fairly linear decline ages 3 -9 , suggesting that striped bass in this range had similar total mortality, even if specific causes varied. Striped bass below age-3 were less represented in Roanoke River catch likely because they had not fully recruited to the spawning population, especially for females (Boyd 2011). Catch-at-age data and our models suggest that individuals age-10 and older (average age-10 female $=880 \mathrm{~mm}$ TL; average age-10 male $=809 \mathrm{~mm} \mathrm{TL}$ ) have lower mortality than younger fish (Fig. 3), likely as a result of a change to an anadromous life history pattern. Callihan et al. (2014) found that AS-RR striped bass $700-800 \mathrm{~mm}$ TL were often caught in coastal areas adjacent to North Carolina and individuals $800 \mathrm{~mm}$ TL and larger were frequently caught in northern coastal waters. We tagged only a few (49 PIT tags, 59 low reward tags, 2 sonic and high reward tags) striped bass $700-900 \mathrm{~mm}$ TL, so our mortality results may not be representative for this transitional size category.

As with all approaches, when using an integrated tagging model to estimate mortality rates it is essential to consider model assumptions. Our results suggest that natural mortality is higher than assumed in recent AS-RR striped bass stock assessments (Takade-Heumacher 2010; Mroch and Godwin 2014). Recent assessment estimates are from a forward projecting catch-at-age model, with data from fishery independent surveys and fishery dependent catch. 
694 In these assessments, natural mortality is assumed to be 0.15 , which is much lower than our 695 average estimate of 0.70 (95\%: $0.58-0.86)$. Potential biases from field sampling that could 696 result in estimates of natural mortality being higher than true values should be considered for all 697 tagging studies and are: 1) tag expulsion (i.e., loss); 2) delayed tagging mortality; 3) emigration 698 to areas not covered by stationary receivers; and 4) less than $100 \%$ reporting of high reward 699 tags. Sonic-tag expulsion has been reported for other fish (Moore et al. 1990; Daniel et al. 700 2009; Boone et al. 2013); however, we did not detect any evidence of sonic tag expulsion (i.e., 701 all striped bass reported showed an expected pattern of sonic detections and sometimes we 702 were able to retrieve the sonic tag from the angler or fisher). We accounted for expulsion of 703 internal anchor and PIT tags by direct estimation. Delayed tagging mortality is difficult to assess 704 and would appear as natural mortality. We would expect delayed tagging mortality to result in a 705 706 less dramatic seasonal pattern than was observed for natural mortality. Emigration to areas without stationary receivers would also appear as natural mortality, since individuals would cease to be detected. We did not detect evidence of such emigration and no tags were reported from other areas, but undetected emigration north to Chesapeake Bay is possible. Random temporary emigration should be accounted for by detection probability. Collapsing live detections into bins (i.e., months) has been observed to bias survival estimation, but this bias is usually small when survival rates are high relative to the estimation period (i.e., survival within a month; Hargrove and Borland 1994; Barbour et al. 2013).

We developed an integrated tagging model to estimate monthly fishing and seasonal natural mortality rates. Our monthly mortality rate estimates inform striped bass biology and our annual estimates could be used in stock assessment to improve management of this

716 economically valuable stock. Our study demonstrates how Bayesian methods make analysis of 717 a complicated integrated model with multiple data sources and nuisance parameters (Fig. 1)

718 manageable. Careful consideration must be made with regard to model assumptions and to the 719 choice of priors. Prior selection for these types of models should receive more study in the 
720 future. Our simulations suggest that both multistate only models and integrated models produce 721 unbiased, accurate, and precise estimates of annual mortality rates, and increasing the number 722 of sonic and high reward tags increases precision and accuracy of annual estimates. Multistate 723 only models with passive or active detections of acoustically tagged individuals with or without 724 external tags have the potential to contribute substantially to fisheries management (Hightower 725 and Harris In Press). In contrast, our integrated model for striped bass demonstrated improved 726 precision for monthly estimates of fishing mortality rates, especially for multiple fishery sectors, 727 as compared to a multistate only model. Although not evaluated by simulation, increased tag 728 returns in an integrated model may improve estimates for multiple fishery sectors. Thus, 729 optimal sample sizes of telemetered fish with high reward tags and fish with low reward tags 730 would depend on the biology of the species (i.e., potential for tag collisions), number of fishery sectors, and funding (i.e., sonic with high reward tags are expensive). This integrated tagging model could be modified to estimate components of natural and fishing mortality for a variety of migratory fish species that support recreational, commercial, and catch-and-release fisheries.

\section{Acknowledgments}

Funding was from North Carolina's Marine Resources Fund, through sales of Coastal Recreational Fishing Licenses. We thank Kevin Dockendorf, Charlton Godwin, and Jeremy McCargo for help with study design and sampling. We thank Ladd Bayliss, Tyler Moore, and Anna Laws for extensive field work. We appreciate Jody Callihan, Patrick Cooney, Michael Fisk, and Jared Flowers for field help. Detections on stationary receivers were incredibly useful; we thank Keith Dunton, Tim Ellis, Dewayne Fox, Benjamin Gahagan, William Hoffman, Michael

742 Loeffler, Mary-Jane James-Pirri and Carter Watterson for sending us detections of our sonic743 tagged striped bass. We appreciate Jason Hightower for GIS support, Wilson Laney for 744 biological and logistical support, and Wendy Moore for administrative support. Sampling was 745 conducted under IACUC protocol 10-145-O. Model code is available from the authors. 


\section{References}

748

749

750

751

752

753

754

755

756

757

758

759

760

761

762

763

764

765

766

767

768

769

770

771

Abadi, F., Gimenez, O., Arlettaz, R., and Schaub, M. 2010. An assessment of integrated population models: bias, accuracy, and violation of the assumptions of independence. Ecology 91(1):7-14.

Bacheler, N.M., Buckel, J.A., Hightower, J.E., Paramore, L.M., and Pollock, K.H. 2009. A combined telemetry-tag return approach to estimate fishing and natural mortality rates of an estuarine fish. Can. J. of Fish. Aquat. Sci. 66(8):1230-1244.

Barbour, A.B., Ponciano, J.M., and Lorenzen, K. 2013. Apparent survival estimation from continuous mark-recapture/resighting data. Methods in Ecol. Evol. 4(9):846-853.

Boyd, J.B. 2011. Maturation, fecundity, and spawning frequency of the Albemarle/Roanoke striped bass stock. M.Sc., Department of Biology, East Carolina University, Greenville, SC.

Bettinger, J.M., Tomaso Jr., J.R., and Isley., J. 2005. Hooking mortality and physiological responses of striped bass angled in freshwater and held in live-release tubes. N. Am. J. Fish. Manage. 25(4):1273-1280.

Bischof, R., Swenson, J.E., Yoccoz, N.G., Mysterud, A., and Gimenez, O. 2009. The magnitude and selectivity of natural and multiple anthropogenic mortality causes in hunted brown bears. J. Anim. Ecol. 78(3):656-665.

Boone, S.S., Divers, S.J., Camus, A.C., Peterson, D.L., Jennings, C.A., Shelton, J.L., and Hernandez, S.M. 2013. Pathological and physiological effects associated with long-term intracoelomic transmitters in captive Siberian sturgeon. N. Am. J. Fish. Manage. 33(5):869-877.

Brownie, C., Anderson, D.R., Burnham, K.P., and Robson, D.S. 1985. Statistical inference from band recovery data: a handbook. $2^{\text {nd }}$ Edition U.S. Fish and Wildlife Service Resource Publication:156 
772 Callihan, J.L., Godwin, C.H., and Buckel, J.A. 2014. Effect of demography on spatial

773

774

775

776

777

778

779

780

781

782

783

784

785

786

787

788

789

790

791

792 distribution: movement patterns of the Albemarle Sound-Roanoke River stock of striped bass (Morone saxatilis) in relation to their recovery. Fish. Bull. 112(2-3): 131-143.

Callihan, J.L., Harris, J.E., and Hightower, J.E. 2015. Coastal migration and homing of Roanoke River Striped Bass. Mar. Coast. Fish. 7(1):301-315.

Carmichael, J.T., Haeseker, S.L., and Hightower, J.E. 1998. Spawning migration of telemetered striped bass in the Roanoke River, North Carolina. Trans. Am. Fish. Soc. 127(2):286297.

Daniel, A.J., Hicks, B.J., Ling, N., and David, B.O. 2009. Acoustic and radio-transmitter retention in Common Carp (Cyprinus carpio) in New Zealand. Mar. Fresh. Res. 60(4):328-333.

Deters, K.A., Brown, R.S., Boyd, J.W., Eppard, M.B., and Seaburg, A.G. 2012. Optimal suturing technique and number of sutures for surgical implantation of acoustic transmitters in juvenile salmonids. Trans. Am. Fish. Soc. 141(1):1-10.

Duriez, O., Saether, S.A., Ens, B.J., Choquet, R., Pradel, R., Lambeck, R.H.D., and Klaassen, M. 2009. Estimating survival and movements using both live and dead recoveries: a case study of oystercatchers confronted with habitat change. J. Appl. Ecol. 46(1):144153.

Gauthier, D.T., Audemard, C.A., Carlsson, J.E.L., Darden, T.L., Denson, M.R., Reece, K.S., and Carlsson, J. 2013. Genetic population structure of US Atlantic coastal striped bass (Morone saxatilis). J. Hered. 104(4):510-520.

Gelman, A., and Hill. J. 2007. Data analysis using regression and multilevel/hierarchical models. New York, New York: Cambridge University Press, 625 pp.

Haeseker, S.L., Carmichael, J.T., and Hightower, J.E. 1996. Summer distribution and condition of striped bass within the Albemarle Sound, North Carolina. Trans. Am. Fish. Soc. 125(5):690-704. 
797

Hargrove, J.W., and Borland, C.H. 1994. Pooled population parameter estimates from markrecapture data. Biometrics 50:1129-1141.

Hassler, W.W., Hill, N.L., and Brown, J.T. 1981. The status and abundance of striped bass, Morone saxatilis, in the Roanoke River and Albemarle Sound, North Carolina, 19561980. North Carolina Department of Natural Resources and Community Development, Division of Marine Fisheries, Special Scientific Report 38, Morehead City.

Hightower, J.E., and Harris, J.E. In Press. Estimating fish mortality rates using telemetry and multistate models. Fisheries.

Hightower, J.E., Jackson, J.R., and Pollock, K.H. 2001. Use of telemetry methods to estimate natural and fishing mortality of striped bass in lake Gaston, North Carolina. Trans. Am. Fish. Soc. 130(1):57-567.

Hightower, J.E., and Pollock, K.H. 2013. Tagging methods for estimating population size and mortality rates of inland striped bass populations. Am. Fish. Soc. Symp. 80:249-262.

Hoenig, J.M., Barrowman, N.J., Hearn, W.S., and Pollock, K.H. 1998a. Multiyear tagging studies incorporating fish effort data. Can. J. of Fish. Aquat. Sci.55(6):1466-1476.

Hoenig, J.M., Barrowman, N.J., Pollock, K.H., Brooks, E.N., Hearn, W.S., and Polacheck, T. 1998b. Models for tagging data that allow for incomplete mixing of newly tagged animals. Can. J. of Fish. Aquat. Sci. 55(6):1477-1483.

Hughes, J.B., and Hightower, J.E. 2015. Combining split-bean and dual-frequency identification sonars to estimate abundance of anadromous fishes in the Roanoke River, North Carolina. N. Am. J. Fish. Manage. 35(2):229-240.

Jiang, H., Pollock, K.H., Brownie, C., Hoenig, J.M., Latour, R.J., Wells, B.K., and Hightower, J.E. 2007. Tag return models allowing for harvest and catch and release: evidence of environmental and management impacts on striped bass fishing and natural mortality rates. N. Am. J. Fish. Manage. 27(2):387-396. 
822 Kendall, W.L., Conn, P.B., and Hines, J.E. 2006. Combining multistate capture-recapture data

823

824

825

826

827

828

829

830

831

832

833

834

835

836

837

838

839

840

841

842

843

844

845

846

847

with tag recoveries to estimate demographic parameters. Ecology 87(1):169-177.

Kéry, M., and Schaub, M. 2012. Bayesian population analysis using WinBUGS. Elsevier, Inc., Waltham, MA.

Kerns, J.A., Allen, M.S., and Harris, J.E. 2012. Importance of assessing population-level impact of catch-and-release mortality. Fisheries 37(11):502-503.

Kerns, J.A., Allen, M.S., and Hightower, J.E. 2016. Components of mortality within a black bass high release recreational fishery. Trans. Am. Fish. Soc. 145(3):578-588.

Kneebone, J., Hoffman, W.S., Dean, M.J., Fox, D.A., and Armstrong, M.P. 2014. Movement patterns and stock composition of adult striped bass tagged in Massachusetts coastal waters. Trans. Am. Fish. Soc. 143(5):1115-1129.

Latour, R.J., Pollock, K.H., Wenner, C.A., and Hoenig, J.M. 2001. Estimates of fishing and natural mortality for subadult red drum in South Carolina waters. N. Am. J. Fish. Manage. 21(4):733-744.

Lorenzen, K. 1996. The relationship between body weight and natural mortality in juvenile and adult fish: a comparison of natural ecosystems and aquaculture. J. Fish Biol. 49(4):627647.

Mather, M.E., Finn, J.T., Ferry, K.H., Deegan, L.A., and Nelson, G.A. 2009. Use of non-natal estuaries by migratory striped bass (Morone saxatilis) in summer. Fish. Bull. 107(3):329388.

Maunder, M.N., and Punt, A.E. 2013. A review of integrated analysis in fisheries stock assessment. Fish. Res. 142:61-74.

McCargo, J.W., and Dockendorf, K.J. 2012. Review of striped bass fisheries and monitoring programs in Roanoke River, North Carolina-2011. Federal Aid in Sport Fish Restoration: Project F-22. North Carolina Wildlife Resources Commission, Division of Inland Fisheries, Raleigh, NC. 
848

McCargo, J.W., and Dockendorf, K.J. 2013. Review of striped bass fisheries and monitoring programs in Roanoke River, North Carolina-2012. Federal Aid in Sport Fish Restoration: Project F-108. North Carolina Wildlife Resources Commission, Division of Inland Fisheries, Raleigh, NC.

McCargo, J.W., and Dockendorf, K.J. 2014. Review of striped bass fisheries and monitoring programs in Roanoke River, North Carolina-2013. Federal Aid in Sport Fish Restoration: Project F-108. North Carolina Wildlife Resources Commission, Division of Inland Fisheries, Raleigh, NC.

Millard, M.J., Mohler, J.W., Kahnle, A., and Cosman, A. 2005. Mortality associated with catchand-release angling of striped bass in the Hudson River. N. Am. J. Fish. Manage. 25(4):1533-1541.

Moore, A., Russell, I.C., and Potter, E.C.E. 1990. The effects of intraperitoneally implanted dummy acoustic transmitters on the behavior and physiology of juvenile Atlantic Salmon, Salmo salar L. J. Fish Biol. 37(5):713-721.

Mroch, R. and Godwin, C. 2014. Stock status of Albemarle Sound-Roanoke River striped bass. North Carolina Division of Marine Fisheries, Morehead City, NC.

Nelson, K. 1998. Catch and release mortality of striped bass in the Roanoke River, North Carolina. N. Am. J. Fish. Manage. 18(1):25-30.

Patrick, W.S., Bin, O., Schwabe, K.A., and Schuhmann, P.W. 2006. Hatchery programs, stock enhancement, and cost effectiveness: A case study of the Albemarle Sound/Roanoke River stocking program 1981-1996. Mar. Policy 30(4):299-307.

Pollock, K.H., Hoenig, J.M., and Jones, C.M. 1991. Estimation of fishing and natural mortality when a staging study is combined with a creel or port sampling. Am. Fish. Soc. Symp. $12: 423-434$. 
872 Pollock, K.H., Hoenig, J.M., Hearn, W.S., and Calingaert, B. 2001. Tag reporting rate

873

874

875

876

877

878

879

880

881

882

883

884

885

886

887

888

889

890

891

892

893

894

895

estimation: 1. An evaluation of the high reward tagging method. N. Am. J. Fish. Manage. 21(3):521-532.

Pollock, K.H., Hoenig, J.M., Hearn, W.S., and Calingaert, B. 2002. Tag reporting rate estimation: 2. Use of high reward tagging and observers in multiple component fisheries N. Am. J. Fish. Manage. 22(3):727-736.

Pollock, K.H., Jiang, H., and Hightower, J.E. 2004. Combining telemetry and fisheries tagging models to estimate fishing and natural mortality rates. Trans. Am. Fish. Soc. 133(3):639648.

Plummer, M. 2003. JAGS: a program for analysis of Bayesian graphical models using Gibbs sampling. In K. Hornik, F. Leisch, and A. Zeileis, editors. Proceedings of the 3rd International Workshop on Distributed Statistical Computing. Vienna, Austria.

R Core Team. 2013. R: A language and environment for statistical computing. R Foundation for Statistical Computing, Vienna, Austria, URL: hppt://www.R-project.org (February 2015).

Rhodes, J.R., Ng, C.F., de Villiers, D.L., Preece, H.J., McAlpine, C.A., and Possingham, H.P. 2011. Using integrated population modelling to quantify the implications of multiple threatening processes for a rapidly declining population. Biol. Conserv. 144(3):10811088.

Rudd, M.B., Ahrens, R.N.M., Pine, W.E., and Bolden, S.K. 2014. Empirical, spatially explicit natural mortality and movement rate estimates for threatened Gulf sturgeon (Acipenser oxyrinchus desotoi). Can. J. of Fish. Aquat. Sci. 71(9):1407-1417.

Secor, D.H., and Piccoli, P.M. 2007. Oceanic migration rates of upper Chesapeake Bay striped bass (Morone saxatilis) determined by otolith microchemical analysis. Fish. Bull. 105(1):62-73. 
896 Sogard, S.M. 1997. Size-selective mortality in the juvenile stage of teleost fishes: A review. Bull. Mar. Sci. 60(3):1129-1157.

898 Takade-Heumacher, H. 2010. Stock status of Albemarle Sound-Roanoke River striped bass.

899 North Carolina Division of Marine Fisheries, Morehead City, North Carolina.

900 Vandergoot, C.S., and Brendan, T.O. 2015. Accuracy and precision of fishery and demographic 901 estimates from a spatial tag-recovery model when inter-regional movements are treated 902 as fixed. Fish. Res. 164:8-25.

903 Waldman, J., Maceda, L., and Wirgin, I. 2012. Mixed-stock analysis of wintertime aggregations 904 of striped bass along the Mid-Atlantic coast. J. Appl. Ichthyol. 28(1):1-6.

905 Waterhouse, L., and Hoenig, J.M. 2011. Instantaneous-rates tagging models for delayed mixing 906 of newly tagged cohorts: Partial year tabulation of recaptures. N. Am. J. Fish. Manage. 907 31(6):995-1004.

908

Wilberg, M.J., and Bence, J.R. 2006. Performance of time-varying catchability estimators in 909 statistical catch-at-age analysis. Can. J. of Fish. Aquat. Sci.63(10):2275-2285. 
1 Table 1. Detections and returns of tagged resident striped bass (excluding tagging mortalities) in the Albemarle Sound-Roanoke

2 River, North Carolina, used to estimate mortality rates by an integrated tagging model.

\begin{tabular}{|c|c|c|c|c|c|c|c|c|c|}
\hline \multirow[b]{2}{*}{ Tag Type } & \multirow[b]{2}{*}{ Number } & \multirow[b]{2}{*}{ Tagging period } & \multirow[b]{2}{*}{ Censored period } & \multicolumn{3}{|c|}{ Number Returned } & \multicolumn{3}{|c|}{ Number Detected } \\
\hline & & & & $20 \overline{11}$ & 2012 & 2013 & $20 \overline{11}$ & 2012 & 2013 \\
\hline Sonic and high reward & 17 & February 2011 & October 2012 & 5 & 2 & 1 & 17 & 11 & 0 \\
\hline Sonic and high reward & 17 & March 2011 & November 2012 & 6 & 0 & 0 & 17 & 7 & 0 \\
\hline Sonic and high reward & 34 & April 2011 & December 2012 & 4 & 2 & 0 & 34 & 12 & 0 \\
\hline Sonic and high reward & 1 & May 2011 & January 2012 & 0 & 0 & 0 & 1 & 1 & 0 \\
\hline Sonic and high reward & 25 & February 2012 & End of study & NA & 6 & 0 & NA & 21 & 5 \\
\hline Sonic and high reward & 9 & March 2012 & End of study & NA & 1 & 1 & NA & 8 & 6 \\
\hline PIT & 727 & April 2011 & NA & NA & NA & NA & 7 & 4 & 3 \\
\hline PIT & 1079 & May 2011 & NA & NA & NA & NA & 1 & 2 & 2 \\
\hline PIT & 987 & April 2012 & NA & NA & NA & NA & NA & 5 & 18 \\
\hline PIT & 760 & May 2012 & NA & NA & NA & NA & NA & 0 & 12 \\
\hline PIT & 77 & April 2013 & NA & NA & NA & NA & NA & NA & 2 \\
\hline Low reward & 622 & April 2011 & NA & 40 & 29 & 3 & NA & NA & NA \\
\hline Low reward & 981 & May 2011 & NA & 25 & 49 & 3 & NA & NA & NA \\
\hline Low reward & 987 & April 2012 & NA & NA & 73 & 22 & NA & NA & NA \\
\hline Low reward & 760 & May 2012 & NA & NA & 20 & 13 & NA & NA & NA \\
\hline Low reward & 77 & April 2013 & NA & NA & NA & 7 & NA & NA & NA \\
\hline Low reward & 384 & May 2013 & NA & NA & NA & 11 & NA & NA & NA \\
\hline
\end{tabular}


Table 2. Description of symbols for (A) indices, data, and (B) estimated parameters (ordered alphabetically) in the integrated model

4 for resident striped bass in the Albemarle Sound-Roanoke River, North Carolina, with prior distribution (when applicable).

5

\begin{tabular}{|c|c|}
\hline Indices & Description \\
\hline$a$ & Ages included in the catch-at-age submodel $(a=3,4, \ldots, 9)$ \\
\hline$c$ & PIT tag $(c=1,2, \ldots, 5)$ or low reward tag $(c=1,2, \ldots, 6)$ cohorts \\
\hline$g$ & Index for months at large before recapture for striped bass tagged with an internal anchor tag $(g=1,2, \ldots, 7)$ \\
\hline$i$ & Telemetered individuals $(i=1,2, \ldots 103)$ \\
\hline$k$ & Experimental samples (Nelson 1998) to evaluate impacts of water temperature on catch and release mortality $(k=1,2, \ldots, 5)$ \\
\hline$n$ & Individuals in each cohort for PIT or low reward tagged individuals \\
\hline$q$ & Quarters based on season $(q=1,2,3,4)$ \\
\hline$s$ & Fishery sectors $(s=1,2, \ldots, 5)$ \\
\hline$t$ & Months $(t=1,2, \ldots, 33)$ \\
\hline$y$ & Spawning run years $(y=1,2,3)$ \\
\hline \multicolumn{2}{|l|}{ Data } \\
\hline$C_{k}^{C R D}$ & Number of $N^{C R D}{ }_{k}$ that died of catch and release mortality in each experimental temperature sample (Nelson 1998) \\
\hline$C_{g}^{I A}$ & Number of $N_{g}^{I A}$ with an intact internal anchor tag \\
\hline$C^{P I T}$ & Number of $N^{P I T}$ with an intact PIT tag \\
\hline$E_{t, s}$ & Number of $\boldsymbol{H}_{t, s}$ examined for a PIT tag by month and fishery sector \\
\hline$H_{t, s}$ & Harvest by month and fishery sector \\
\hline$H_{y, 1,2}$ & Total catch $\left(H_{y, 1}\right)$ and harvest $\left(H_{y, 2}\right)$ in the Roanoke River during each spawning run year \\
\hline$N^{A G E} a y$ & Number of individuals in each age class during each spawning run year (from scales) \\
\hline$N_{k}^{C R D}$ & Number sampled to estimate catch and release mortality by experimental temperature sample (Nelson 1998) \\
\hline$N^{I A}{ }_{g}$ & Number recaptured to estimate monthly rate of tag retention for internal anchor tags \\
\hline$N^{P I T}$ & Number recaptured to estimate PIT tag retention \\
\hline$R^{L R T}{ }_{c}$ & Number tagged with a low reward tag by cohort \\
\hline$R^{P I T}{ }_{c}$ & Number tagged with a PIT tag by cohort \\
\hline$V_{n, c}^{L R T}$ & Proportion of the release month available for each individual in the low reward tag cohort \\
\hline$V_{n, c}^{P I T}$ & Proportion of the release month available for each individual in the PIT tag cohort \\
\hline & Water temperature in experimental samples (Nelson 1998) to evaluate impacts on catch and release mortality \\
\hline & Monthly water temperature at the USGS gauging station at Halifax in the Roanoke River \\
\hline$X^{L R T} c, t, s$ & Tag return matrix for low reward tags \\
\hline$X_{c, t, s}^{P I T}$ & Tag return matrix for PIT tags \\
\hline$Y_{i, t}$ & Capture history matrix for all telemetered individuals \\
\hline$\sigma_{y, 1,2}^{H A R}$ & Standard deviation on total catch $\left(\sigma_{y, 1}^{H A R}\right)$ and harvest $\left(\sigma_{y, 2}^{H A R}\right)$ in the Roanoke River during each spawning run year \\
\hline
\end{tabular}




\begin{tabular}{|c|c|c|}
\hline Parameters & Description & Prior (if applicable) \\
\hline$A_{y, 1,2}$ & Total $\left(A_{y, 1}\right)$ and harvestable $\left(A_{y, 2}\right)$ run size estimates by spawning run year & \\
\hline$F_{t, s=1,2, \ldots, 5}$ & Monthly fishing mortality rates for the five (1-5) sectors (Priors on natural log scale) & Uniform $(-10,1)$ \\
\hline$F_{t}^{C R}$ & Monthly fishing mortality due to catch and release & \\
\hline I & Monthly tag retention rate for internal anchor tags & Uniform $(0,1)$ \\
\hline M & Study-wide annual instantaneous natural mortality of resident striped bass & \\
\hline$M_{a}$ & Average monthly natural mortality estimated quarterly (Prior on natural log scale) & Uniform $(-10,1)$ \\
\hline$P_{c R T}^{L R T}$ & Return probabilities for low reward tags & \\
\hline$P_{c, t, s}^{P I T}$ & Detection probabilities for PIT tags & \\
\hline$p_{t}^{L I V E}$ & Monthly detection probability for telemetered individuals & Uniform $(0,1)$ \\
\hline$p^{N M}{ }^{\tau}$ & Detection probability for natural mortality & Uniform $(0,1)$ \\
\hline$Q_{i, t}$ & Estimated "true" states for all telemetered individuals during all months & \\
\hline$S_{t, s}$ & Proportion of harvested PIT tags that were scanned & Uniform $(0,1)$ \\
\hline$T_{t}$ & Monthly instantaneous removal of internal anchor tags & \\
\hline$Z$ & Study-wide annual instantaneous total mortality of resident striped bass & \\
\hline$Z_{t}$ & Monthly total instantaneous mortality of resident striped bass & \\
\hline$\alpha$ & Intercept for the catch curve in the catch-at-age submodel & Uniform $(0,20)$ \\
\hline$\beta_{1,2}$ & Intercept $\beta_{1}$ and slope $\beta_{2}$ for the logistic likelihood model of temperature on catch and release mortality & Normal $(0,0.01)$ \\
\hline$\gamma$ & Non-mixing during the month of release for low reward and PIT tagged fish & Uniform $(0,1)$ \\
\hline$\delta$ & PIT tag retention rate & Uniform $(0,1)$ \\
\hline$\lambda_{12}$ & Reporting rates for the commercial $\left(\lambda_{1}\right)$ and recreational $\left(\lambda_{2}\right)$ fisheries & Uniform $(0,1)$ \\
\hline $\boldsymbol{\theta}_{Q_{i, t}, 1,2, \ldots, 8}$ & The eight observation probabilities for the nine true states in the multistate submodel & \\
\hline$\mu^{A G E}$ & Expected natural log of the number of fish by age and spawning run year & \\
\hline$\mu^{L R T}$ & Mean proportion of the month remaining after release by cohort for low reward tags & Uniform $(0,1)$ \\
\hline$\mu^{P I T}{ }_{c}^{c}$ & Mean proportion of the month remaining after release by cohort for PIT tags & Uniform $(0,1)$ \\
\hline$\sigma^{A G E}$ & Standard deviation on $\mu_{a, y}^{A G E}$ & Uniform $(0,10)$ \\
\hline$\sigma^{L R T}{ }_{c}$ & Standard deviation on $\mu^{L R T}{ }_{c}^{a, y}$ & Uniform $(0,20)$ \\
\hline$\sigma^{P I T}{ }_{c}$ & Standard deviation on $\mu^{P I T}{ }_{c}^{c}$ & Uniform $(0,20)$ \\
\hline$\phi^{L R T}{ }_{c t}$ & Cumulative survival for low reward-tagged individuals in a cohort from tagging until month $t$ & \\
\hline$\phi_{c, t}^{P I T}$ & Cumulative survival for PIT-tagged individuals in a cohort from tagging until month $t$ & \\
\hline & Probability of death due to catch and release as a function of water temperature & \\
\hline$\Omega_{Q_{i, t}, 1,2, \ldots, 9}$ & Probabilities to transition into each of the nine true states for the multistate submodel & \\
\hline
\end{tabular}


9 Table 3. Parameter values (i.e., monthly estimates from the integrated model for resident

10 striped bass in the Albemarle Sound-Roanoke River, North Carolina) used in simulation

11 analyses to evaluate a multistate and an integrated model to estimate mortality rates.

\begin{tabular}{|c|c|c|c|}
\hline Period & Fishing mortality $\left(F_{t}\right)$ & Natural mortality $\left(M_{e}\right)$ & Detection probability $\left(p^{L I V E}{ }_{t}\right)$ \\
\hline 1 & 0.151 & 0.007 & 0.953 \\
\hline 2 & 0.007 & 0.007 & 0.989 \\
\hline 3 & 0.006 & 0.007 & 0.989 \\
\hline 4 & 0.008 & 0.185 & 0.755 \\
\hline 5 & 0.004 & 0.185 & 0.681 \\
\hline 6 & 0.003 & 0.185 & 0.633 \\
\hline 7 & 0.019 & 0.002 & 0.747 \\
\hline 8 & 0.018 & 0.002 & 0.779 \\
\hline 9 & 0.022 & 0.002 & 0.675 \\
\hline 10 & 0.024 & 0.001 & 0.854 \\
\hline 11 & 0.019 & 0.001 & 0.859 \\
\hline 12 & 0.144 & 0.001 & 0.874 \\
\hline 13 & 0.162 & 0.003 & 0.966 \\
\hline 14 & 0.011 & 0.003 & 0.824 \\
\hline 15 & 0.005 & 0.003 & 0.692 \\
\hline
\end{tabular}

12 
13 Table 4. Total spawning run size and harvestable run size estimates (with $95 \%$ credible

14 intervals) for striped bass in the Roanoke River, North Carolina, by spawning year.

\begin{tabular}{lll}
\hline Year & Total Run & Harvestable Run \\
\hline 2011 & $694993(399373-1195197)$ & $214792(111118-411780)$ \\
2012 & $498881(333254-747793)$ & $281350(169423-440971)$ \\
2013 & $715185(397160-1204808)$ & $140756(53540-288071)$ \\
\hline
\end{tabular}

15

16 


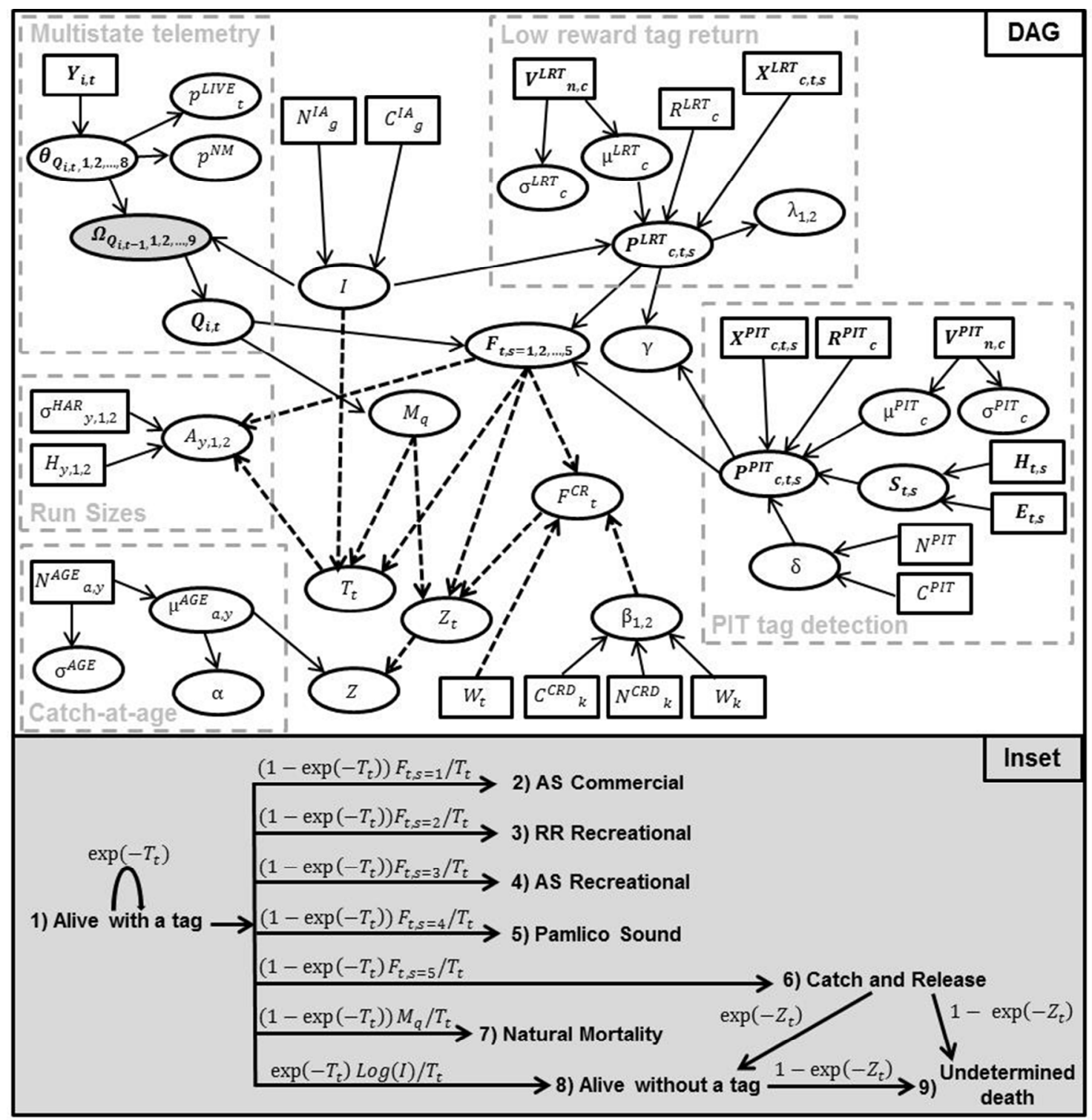

Fig. 1. Directed acyclic graph (DAG) for the integrated model to estimate mortality rates and run sizes for resident striped bass in the Albemarle Sound-Roanoke River, North Carolina. Ovals represent estimated parameters and boxes represent datasets. Solid arrows indicate stochastic relationships and dashed arrows indicate deterministic relationships (i.e., functions). Dashed boxes indicate the portion of the integrated model described within. The inset illustrates relationships among and transition equations between all estimated true states (with numbers corresponding to descriptions in the text) in the multistate telemetry submodel, illustrated by the larger grey oval in the DAG. Datasets, estimated parameters, and indices are in Table 2. 


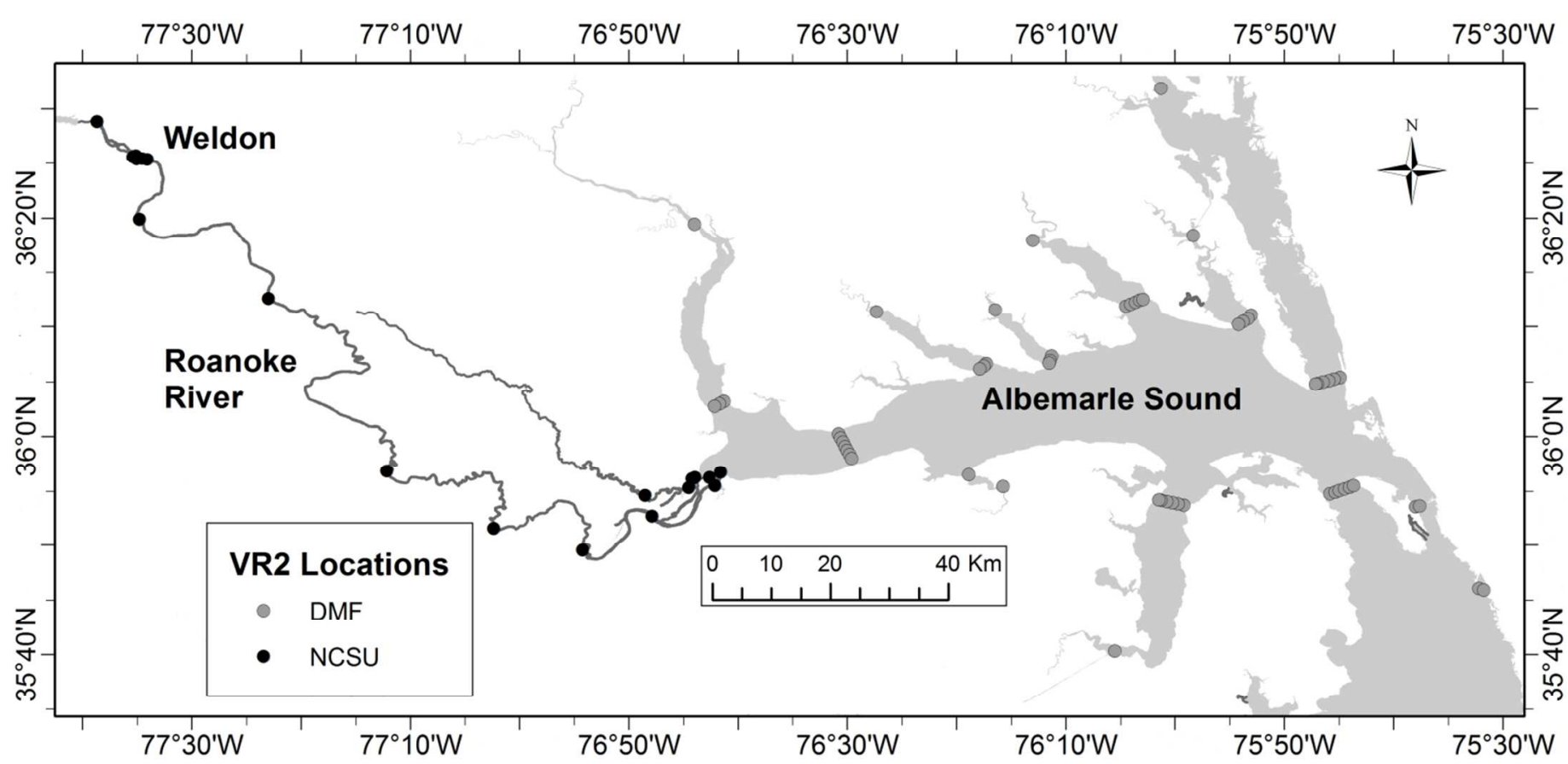

27 Fig. 2. Locations of stationary receivers (VR2 Locations) in North Carolina from North Carolina State University (NCSU) in the

28 Roanoke River (black dots) and North Carolina Division of Marine Fisheries (DMF) in the Albemarle Sound (grey dots). The

29 Basemap for the Roanoke River and Albemarle Sound were from 1:24,000-scale detailed hydrography data located in the NC

30 OneMap Geospatial Portal originated and published by the NC Center for Geographic Information and Analysis. 


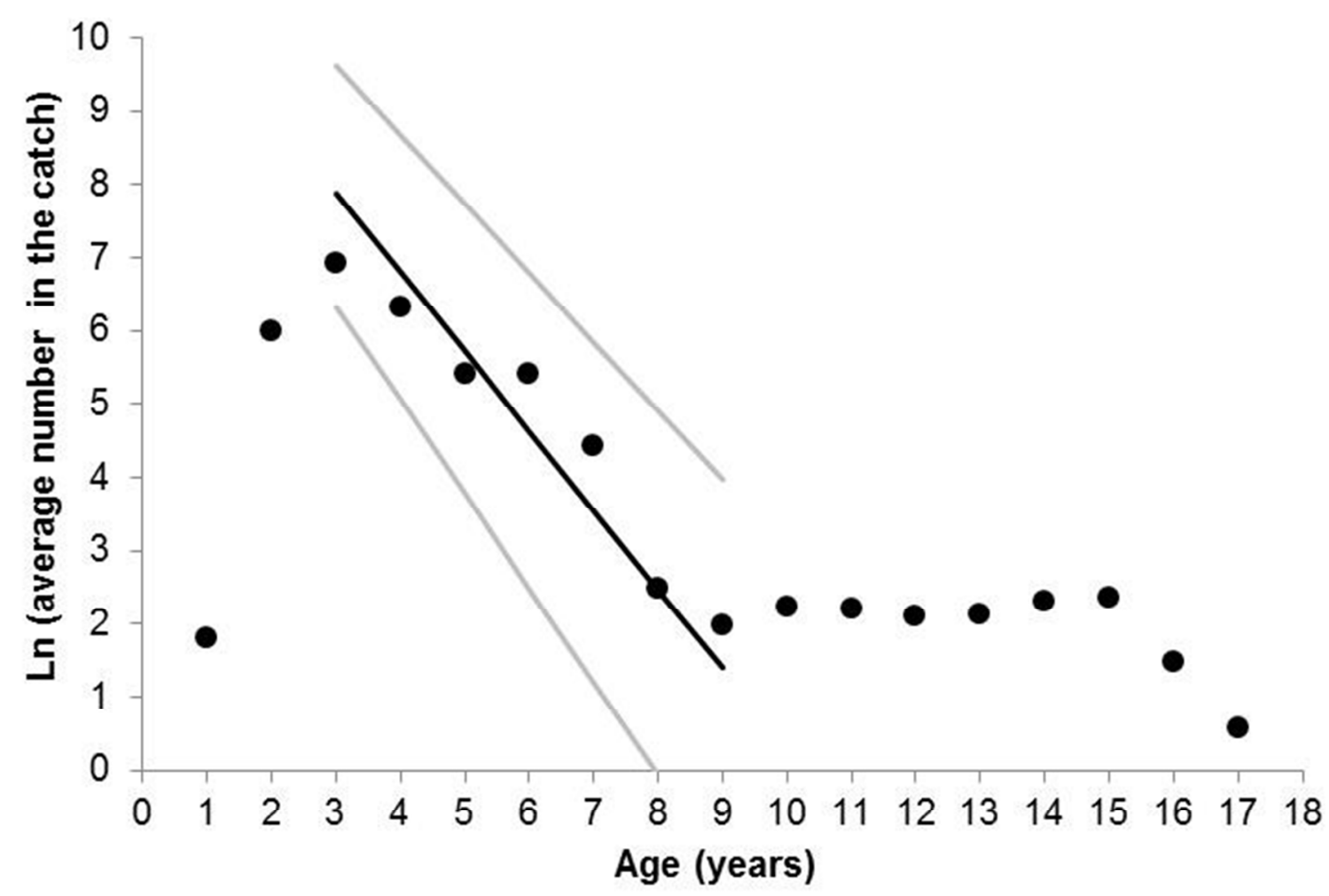

32 Fig. 3. Natural log of average catch-at-age from scales of striped bass caught during spring 33 spawning surveys (2011-2013) by North Carolina Wildlife Resources Commission and North

34 Carolina Division of Marine Fisheries in the Roanoke River, North Carolina (black dots), with 35 expected natural log of catch-at-age (black line) and 95\% credible intervals (grey lines) from the 36 integrated model for resident striped bass in the Roanoke River-Albemarle Sound, North 37 Carolina. 


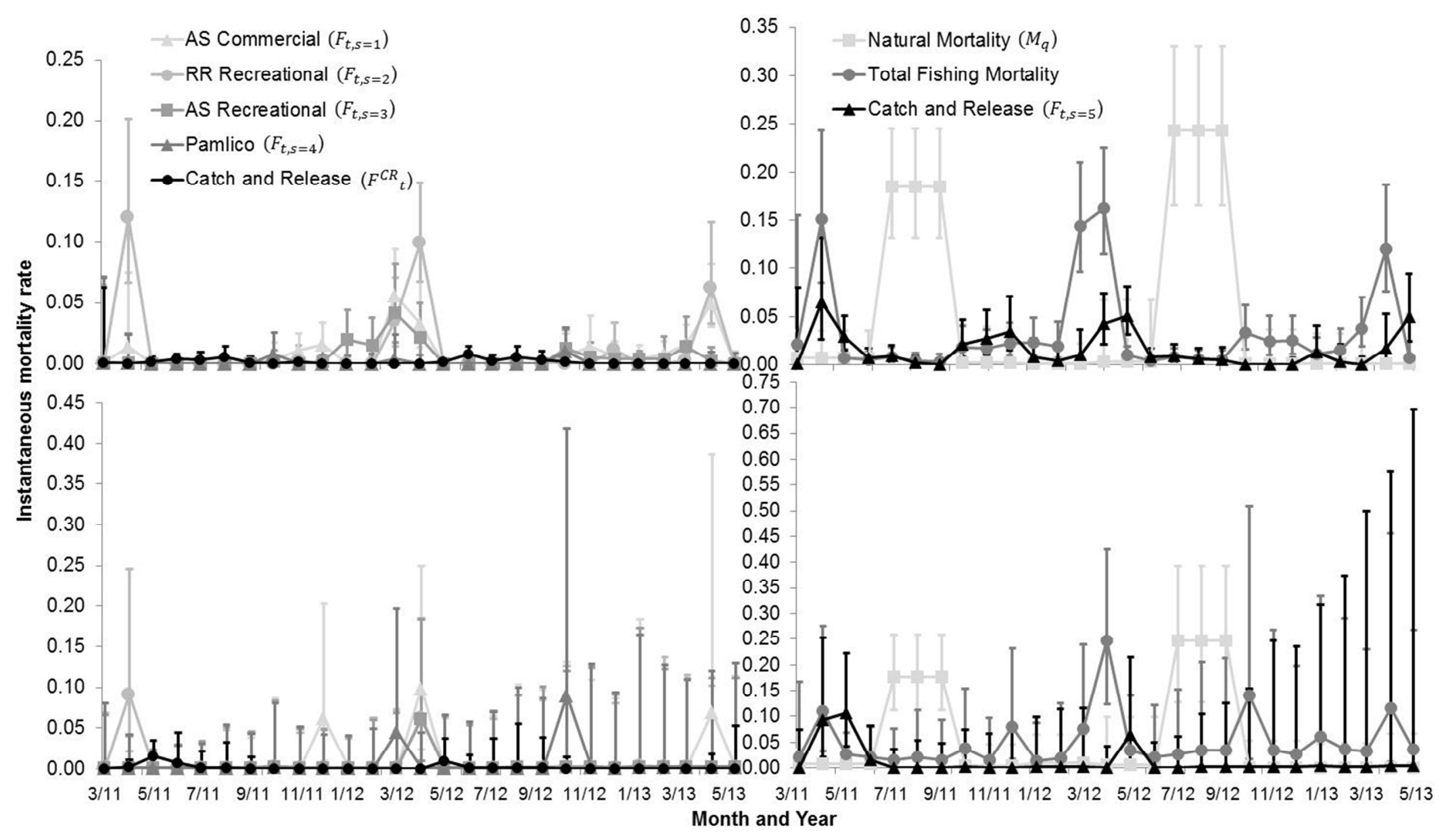

39 Fig. 4. Monthly mortality rates (error bars illustrate $95 \%$ credible intervals) by fishery sector, as well as natural mortality, total fishing

40 mortality (i.e., sum of $F_{t, s=1,2,3,4}$ and $F^{C R}$ ) and catch and release for resident striped bass in the Albemarle Sound-Roanoke River

41 system, North Carolina, estimated by an integrated model (upper panels) and the multistate only model (lower panels). Note:

42 different $y$-axis ranges. 


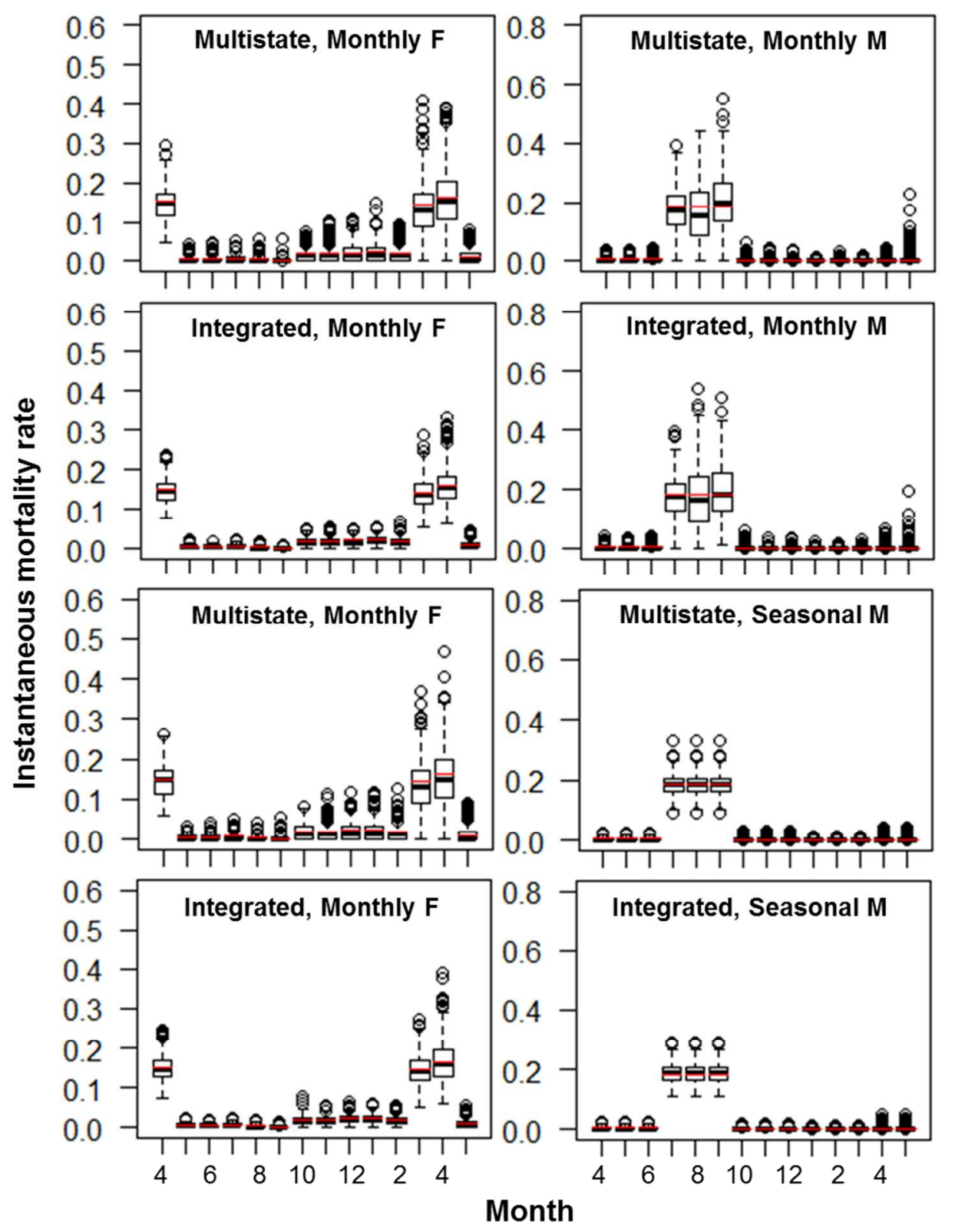

Month

Fig 5. Boxplots of monthly fishing ("F") and natural ("M") mortality rate estimates from simulated models (each row is a model). Rows 1 and 3 are from multistate only models with high reward tags and telemetry ("Multistate"). Rows 2 and 4 are from integrated models with the same

47 multistate component, but also a low reward tag return component ("Integrated”). Models

48 estimated either monthly (rows 1 and 2) or seasonal (rows 3 and 4) values for M. Red lines 49 indicate true simulated monthly mortality rates. 

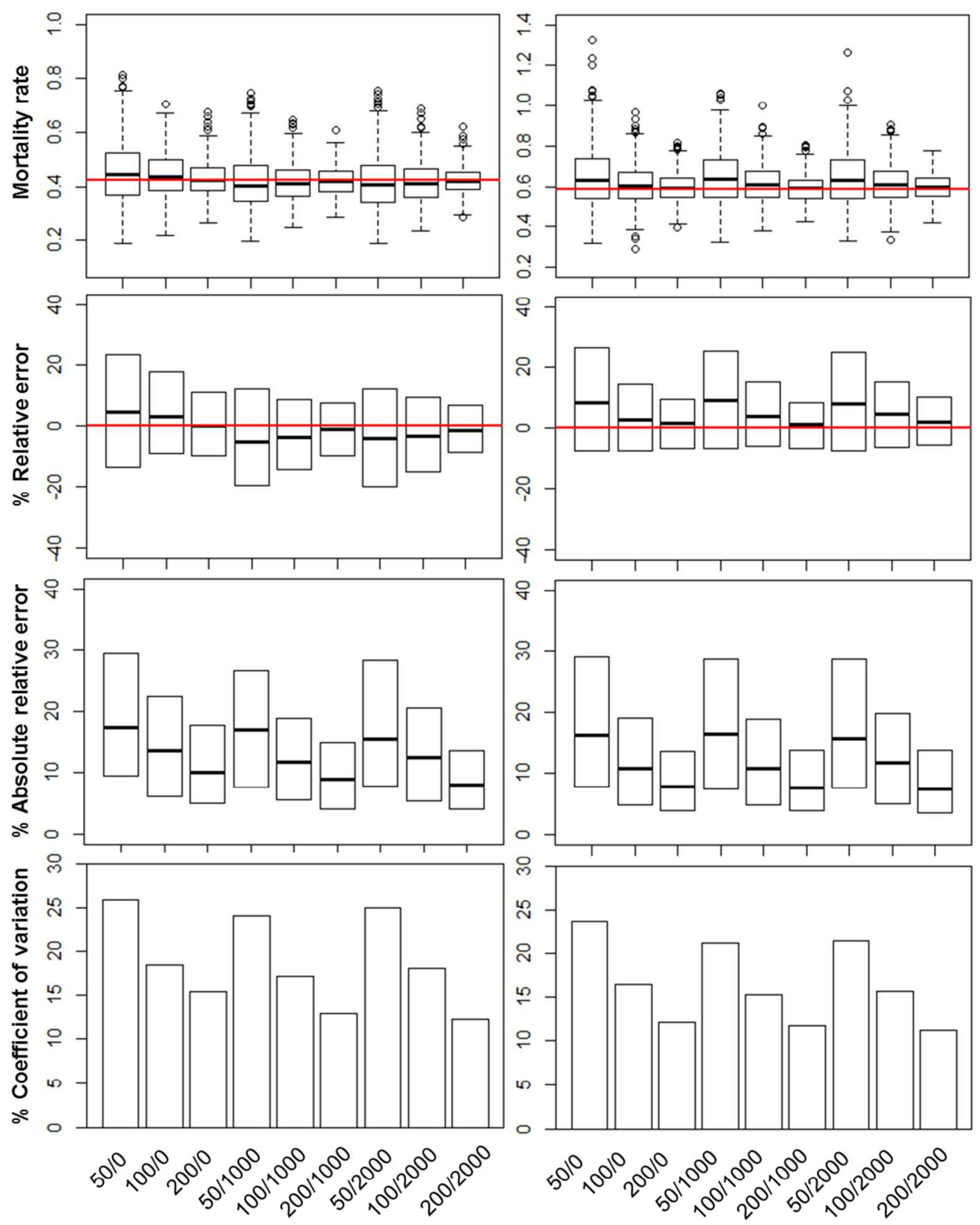

Number of sonic and high reward tags/ number of low reward tags

51 Fig 6. Boxplots of estimates (upper panels), interquartile ranges of percent relative error and

52 percent absolute relative error (middle panels), and percent coefficients of variation (lower

53 panels) of annual instantaneous fishing (left panels) and natural (right panels) mortality rates

54 from simulated models with different sample sizes of fish with sonic and high reward tags, and

55 fish with low reward tags. Each red line indicates the true simulated rate or a median relative

56 error of zero. 